\title{
Investigation of Gama Ray Shielding Properties of the (Al:Si) and (Al+Na):Si doped International Simple Glasses (ISG) using Phy-X/PSD and SRIM Software's
}

Miraç KAMIŞLIOĞLU ( $\nabla$ mkamislioglu@bandirma.edu.tr)

Bandirma Onyedi Eylul Universitesi https://orcid.org/0000-0002-0666-8832

\section{Research Article}

Keywords: Phy-X/PSD, Radiation shielding parameter, (Al:Si) and (Al+Na):Si doped, Glasses

Posted Date: February 23rd, 2021

DOl: https://doi.org/10.21203/rs.3.rs-236805/v1

License: (9) This work is licensed under a Creative Commons Attribution 4.0 International License.

Read Full License

Version of Record: A version of this preprint was published at Journal of Materials Science: Materials in Electronics on April 13th, 2021. See the published version at https://doi.org/10.1007/s10854-021-059048. 


\title{
Investigation of Gama Ray Shielding Properties of the ( $\mathrm{Al}: \mathrm{Si})$ and $(\mathrm{Al}+\mathrm{Na}): \mathrm{Si}$ doped International Simple Glasses (ISG) using Phy-X/PSD and SRIM Software's
}

\author{
M. Kamislioglu ${ }^{1}$ \\ ${ }^{1}$ Bandirma Onyedi Eylul University, Vocational School of Health Services, Medical Imaging \\ Department, 10200, Bandırma, Turkey
}

Corresponding Author: mkamislioglu@bandirma.edu.tr

\begin{abstract}
In this investigation, the gamma photon shielding properties for the ( $\mathrm{Al}: \mathrm{Si})$ and $(\mathrm{Al}+\mathrm{Na}): \mathrm{Si}$ dopped ISG glasses were investigated by using Photon Shielding and Dosimetry (Phy-X / PSD) software for the selected energy range. The obtained results showed that the highest MAC value belong to ISG-A00N glass. It was seen that the MAC values which were examined at all energies changed in harmony with WinXCom. Substituting an atomic fraction of $(\mathrm{Al}: \mathrm{Si})$ with $(\mathrm{Al}+\mathrm{Na})$ :Si resulted in a reduction of the total atomic cross-section of the glass, which lowered the mass attenuation coefficient (MAC). In this study, computations were made for glasses with $\mathrm{SiO}_{2}, \mathrm{Al}_{2} \mathrm{O}_{3}, \mathrm{~B}_{2} \mathrm{O}_{3}, \mathrm{Na}_{2} \mathrm{O}, \mathrm{CaO}$ and $\mathrm{ZrO}_{2}$ content given with ISG-C, ISG-A00, ISG-A12, ISG-A22, ISG-A00N, ISG-A11N, ISG-A18N and ISG-A23N codes. MAC, LAC, HVL, TVL, $Z_{\text {eff }}, N_{\text {eff }}, C_{\text {eff }} Z_{\text {eq }}$, EBF, EABF and FNRCS calculations were applied to assess the radiation protection parameters by using Phy-X/PSD software. In addition, MSP and PR values were calculated by using the SRIM code. In fact, each obtained parameter provides us very important information on radiation protection, and these methods are frequently used in the literature. ISG-A00N glasses were observed to have the highest attenuation coefficient. Thus, the MAC value gradually decreased as the Al, Na and Si contents increased. Likewise, the HVL, TVL and MFP values changed coherent with this. Moreover, $Z_{\text {eff }}$ and $N_{\text {eff }}$ values were seen in the ISG-A00N sample to take the maximum values to each other inversely. The most effective glass sample was seen as ISG-A00N glass at the mean free path penetration power of MSP and PR values. When all the results were evaluated, ISG-A00N glass which has the highest $\mathrm{Si}$ and $\mathrm{Ca}$ contents and density was found to be the glass with the best radiation shielding feature. It is also noteworthy that this glass does not contain any $\mathrm{Al}$ component. As the results of the investigation, it was found out that a very small doped of the Si increases the radiation shielding feature on the glass. It was seen that the ISG-A23N had the lowest $\sum \mathrm{R}$ value. The obtained results revealed that the ISG-A00N>ISG-A00>ISG-C>ISG-A12>ISG-A11N>ISGA22>ISG-A18N>ISG-A23N samples, in ascending order that attenuators for low energy radiations.
\end{abstract}

Keywords: Phy-X/PSD, Radiation shielding parameter, (Al:Si) and (Al+Na):Si doped, Glasses. 


\section{Introduction}

Climate change has become a problem in many countries day by day and this fact confirms the necessity of using nuclear power plants, which are actually source of alternative energy. Although the Three Mile Island, Chernobyl and Fukushima Daiichi nuclear accidents cause concern over these plants, over the past 60 years, great advances have been provided in waste management using nuclear power plants. In order to dispose of these wastes, many studies have been conducted in most countries for a long-term and reliable solution $[1,2]$.

Nuclear waste management is quite difficult process since high radioactive isotopes are produced in the existing power plants. These radioactive isotopes have longevity and risk of toxicity. Most countries have been developing various strategies for waste management and control they keep on conducting studies to produce durable and strong materials. Besides natural radiation, it is vital to use highly protective materials in waste management in order to minimize the environmental risks of ionizing radiation produced by human hands. The most significant impacts of ionizing radiation can be seen in this high radiation wastes. Therefore, it is very crucial the correct management of this high radiation wastes. International simple glass (ISG) can be produced as an alternative to traditional methods. Therefore, ISGs should be developed for all systems by using advanced technology in waste management. International simple glass (ISG) has become the reference for borosilicate glasses over the past few years. In this investigation, the gamma-ray radiation shielding feature of structures that are referred to as ISG glasses in the literature produced by Lu were investigated. These glasses are preferred because of their good radioactive release rate, corrosion resistance and suitable $\mathrm{pH}[1,3]$. The main purpose of this study is to examine the nuclear shielding properties for $\mathrm{Al}$ : $\mathrm{Si}$ and $(\mathrm{Al}+\mathrm{Na}): \mathrm{Si}$ in a nuclear waste model glass (ISG, international simple glass) [4].

According to the recent studies in literature, the materials which are relatively lightweight, accessible, non-toxic, cheap, having a high thermal resistance of shielding performance, improve the known disadvantages of concrete [5]. One of the prominent structures in these studies are glass or glassy materials, which have many advantages in terms of radiation shielding. These materials especially due to their superior features such as transparency, attenuating gamma photons, and ease of use in new generation technological fields, they attract a lot of attention among alternative and innovative glassing materials $[1,6]$.

Since the Phy-X / PSD software was used in this study, the analysis of the effective parameter in the radiation protection of the materials was processed faster. The use of this software is more advantageous for the user in the terms of time. In this study, the protection efficiency at the energy ranges from 0.15 to $15 \mathrm{MeV}$ of $\mathrm{SiO}_{2}, \mathrm{Al}_{2} \mathrm{O}_{3}, \mathrm{~B}_{2} \mathrm{O}_{3}, \mathrm{Na}_{2} \mathrm{O}, \mathrm{CaO}, \mathrm{ZrO}_{2}$ glasses were investigated by using the software 
known as Phy-X / PSD that was produced by Şakar et al., [7,8]. Also, MSP and PR values were calculated in energy ranges from 0.1-20 MeV by using SRIM software [9-11].

\section{Materials and Methods}

Sample codes, chemical properties, densities, and composition ratios of $\mathrm{SiO}_{2}, \mathrm{Al}_{2} \mathrm{O}_{3}, \mathrm{~B}_{2} \mathrm{O}_{3}, \mathrm{Na}_{2} \mathrm{O}, \mathrm{CaO}$, $\mathrm{ZrO}_{2}$ glasses which were previously produced by Lu et al. are given in following [5]. The Phy-X / PSD software which was improved by Şakar et al. can be used as open-source code and online [7]. The chemical compositions of the glass materials were given prepared glasses according to this content $\left(\mathrm{SiO}_{2}, \mathrm{Al}_{2} \mathrm{O}_{3}, \mathrm{~B}_{2} \mathrm{O}_{3}, \mathrm{Na}_{2} \mathrm{O}, \mathrm{CaO}, \mathrm{ZrO}_{2}\right)$. Phy-X / PSD software was created with the NodeJS v8.4.0 program, which serves between server and client-browser with Nginx 1.15 .8 security, and was built on 256-bit PositiveSSL. Determining X-rays and gamma rays passing through a material is very crucial to comprehend the gamma-rays radiation shielding features of the glasses. Many studies have been carried out using $\mathrm{Si}, \mathrm{Al}, \mathrm{Na}, \mathrm{Ca}$ and $\mathrm{Zr}$ glasses in various ratios [2,4,12-14]. In this study, the codes in following are used for the selected glasses:

ISG-C: $60.09 \mathrm{SiO}_{2}+3.84 \mathrm{Al}_{2} \mathrm{O}_{3}+15,96 \mathrm{~B}_{2} \mathrm{O}_{3}+12.65 \mathrm{Na}_{2} \mathrm{O}+5.73 \mathrm{CaO}+1.72 \mathrm{ZrO}_{2}, \rho=2.52 \mathrm{~g} / \mathrm{cm}^{3}$

ISG-A00: $62.58 \mathrm{SiO}_{2}+0 \mathrm{Al}_{2} \mathrm{O}_{3}+15.37 \mathrm{~B}_{2} \mathrm{O}_{3}+12.18 \mathrm{Na}_{2} \mathrm{O}+5.52 \mathrm{CaO}+1.66 \mathrm{ZrO}_{2}, \rho=2.50 \mathrm{~g} / \mathrm{cm}^{3}$

ISG-A12: $49.13 \mathrm{SiO}_{2}+11.98 \mathrm{Al}_{2} \mathrm{O}_{3}+17.21 \mathrm{~B}_{2} \mathrm{O}_{3}+13.64 \mathrm{Na}_{2} \mathrm{O}+6.18 \mathrm{CaO}+1.85 \mathrm{ZrO}_{2}, \rho=2.47 \mathrm{~g} / \mathrm{cm}^{3}$

ISG-A22: $36.29 \mathrm{SiO}_{2}+21.51 \mathrm{Al}_{2} \mathrm{O}_{3}+18.68 \mathrm{~B}_{2} \mathrm{O}_{3}+14.80 \mathrm{Na}_{2} \mathrm{O}+6.71 \mathrm{CaO}+2.01 \mathrm{ZrO}_{2} \rho=2.49 \mathrm{~g} / \mathrm{cm}^{3}$

ISG-A00N: $67.78 \mathrm{SiO}_{2}+0 \mathrm{Al}_{2} \mathrm{O}_{3}+15.96 \mathrm{~B}_{2} \mathrm{O}_{3}+8.81 \mathrm{Na}_{2} \mathrm{O}+5.73 \mathrm{CaO}+1.72 \mathrm{ZrO}_{2} \rho=2.46 \mathrm{~g} / \mathrm{cm}^{3}$

ISG-A11N: $45.56 \mathrm{SiO}_{2}+11.11 \mathrm{Al}_{2} \mathrm{O}_{3}+15.96 \mathrm{~B}_{2} \mathrm{O}_{3}+19.92 \mathrm{Na}_{2} \mathrm{O}+5.73 \mathrm{CaO}+1.72 \mathrm{ZrO}_{2}, \rho=2.53 \mathrm{~g} / \mathrm{cm}^{3}$

ISG-A18N: $31.01 \mathrm{SiO}_{2}+18.38 \mathrm{Al}_{2} \mathrm{O}_{3}+15.96 \mathrm{~B}_{2} \mathrm{O}_{3}+27.19 \mathrm{Na}_{2} \mathrm{O}+5.73 \mathrm{CaO}+1.72 \mathrm{ZrO}_{2}, \rho=2.54 \mathrm{~g} / \mathrm{cm}^{3}$

ISG-A23N: $21.77 \mathrm{SiO}_{2}+23.00 \mathrm{Al}_{2} \mathrm{O}_{3}+15.96 \mathrm{~B}_{2} \mathrm{O}_{3}+31.81 \mathrm{Na}_{2} \mathrm{O}+5.73 \mathrm{CaO}+1.72 \mathrm{ZrO}_{2}, \rho=2.52 \mathrm{~g} / \mathrm{cm}^{3}$

Mass attenuation coefficient (MAC), linear attenuation coefficient (LAC), mean free path (MFP), halfvalue layer (HVL), tenth-value layer (TVL), effective atomic numbers ( $Z_{\text {eff }}$, effective electron density $\left(\mathrm{N}_{\text {eff }}\right)$, effective conductivity $\left(\mathrm{C}_{\mathrm{eff}}\right)$, equivalent atomice number $\left(\mathrm{Z}_{\mathrm{eq}}\right)$, exposure buildup factor $(\mathrm{EBF})$ and fast neutron removal cross-section (FNRCS) values can be calculated in the energy range of $0.015 \mathrm{MeV}$ 
to $100 \mathrm{GeV}$ by using the Phy-X / PSD software [7,8]. For more detailed information, it can be examined the open-source software using the following link: https://phy-x.net/PSD. In the present study, it has been examined the role of $\mathrm{Al}-\mathrm{Si}$ and ( $\mathrm{Al}-\mathrm{Si}$ ): $\mathrm{Na}$ doped glasses in radiation protection. Basically, the Phy-X / PSD program has been used to calculate easily the radiation attenuation characteristic of various elements and compounds [15]. The following steps were applied to use this software;

- By entering the component and density values of the glasses in the Phy-X / PSD program, the samples were introduced to the system,

- The Energy values that have been selected,

- Calculation methods were selected,

the current research was conducted in the wide energy region of $0.15-15 \mathrm{MeV}$ for the specified glasses by using Phy-X / PSD software [16-18].

\section{Results and Discussion}

In this study, the methods used to discuss the radiation shielding properties of the glassy systems were given in the following order.

\subsection{MAC and LAC}

The LAC refers to the attenuated fraction of photons passing through a certain thickness of the material [19]. In order to calculate the LAC value, it is necessary to look at the interactions between the material and ionizing radiation (Photoelectric effect-PE, Compton scattering-CS and Rayleigh scattering-RS). The Beer-Lambert Law equation has been used to calculate the LAC value as in the following:

$I=I_{0} e^{-\mu x}=I_{0} e^{-\mu_{m} t}$

where the $I$ has been attenuated, and also the $I_{0}$ has been unattenuated photon densities respectively. The $\mu$ value represents the LAC value which is given by $\left(\mathrm{cm}^{-1}\right)$ [20]. LAC values were computed for the 0.015-15 MeV gamma energy range. The graph of the obtained LAC values is shown in Figure 1. As seen in the results, the changes of the LAC values are subject to the energy range and the properties of 
the chemical composition of the glasses. In Figure 1, it can be seen explicitly that LAC had the highest value for ISG-A00N glass and the lowest value for ISG-A23N glass. In addition, as we examined the graph in detail, the calculated LAC value appears as a different LAC function curve for different energy regions. The reason that the change of the LAC function is due to the different interactions of the material with the gamma photon for the investigated energy regions.

The MAC value indicates the capacity of ionizing photons passing through the material of a certain thickness. The MAC value of alloy, compound, or mixture systems can be calculated by using the following mathematical equation:

$\mu_{m}=\left(\frac{\mu}{\rho}\right)=\sum_{i} w_{i}(\mu / \rho)_{i}$

where $\mu_{m}$ is the MAC value, $\rho$ is the density value of the material, and $w_{i} \mathrm{i}^{\text {th }}$ is the fractional weight of the element. The MAC value is one of the most basic calculation methods in radiation protection studies as it gives the measure of the direct interaction of ionizing radiation with the material [21]. In this point of view, the investigation of MAC value in radiation physics, medical radiation, radiotherapy, and nuclear studies has been used widely. The MAC value is acquired by dividing the LAC value by the density of the glasses. The MAC graph drawn for the glass samples is given in Figure 2. Obviously, the LAC and MAC function is the same as the tendencies of change. The MAC had the highest value for ISG-A00N glass and the lowest value for ISG-A23N glass.

\subsection{MFP, HVL and TVL}

The MFP expresses the average distance between the material and a photon that passes through the barrier before interacting and it is an important calculation method that is considered in radiation shielding studies $[8,23]$. It is determined according to the formula given below by considering the value of $\mu . M F P=(1 / \mu)$

MFP value varies as a function of photon energy. As seen in the graph, the change in MFP value increases up to approximately $10 \mathrm{MeV}$ energy. ISG-A00N glasses had the highest MFP value, and ISG- 
A23N glasses took the lowest MFP value. The calculated results show that the change of MFP value depends on the chemical properties of the compound. It can be seen clearly in Figure 3. that when the $\mathrm{Si}$ and $\mathrm{Na}$ additive ratio in the glass component is increased, the MFP value of the materials decreased.

The HVL $(\mathrm{cm})$ and TVL $(\mathrm{cm})$ values, as in the MFP value, are also calculated to determine the thickness of the glasses to reduce the amount of radiation. These parameters can be used as an alternative method to confirm the best radiation shielding material. The HVL value gives the value of the distance at which the radiation is weakened by $50 \%$ as it passes through the material. Meanwhile, the TVL value gives the value of the distance at which radiation is weakened by $90 \%$ as it passes through the material $[22,24]$. For the computation of the HVL and TVL values the following equations can be used:

$H V L=(\ln 2 / \mu)$

In addition, the TVL value can be given with the following equation.

$T V L=(\ln 10 / \mu)$

The graphs calculated for the HVL and TVL values are given in Figure 4. and 5., respectively. As seen clearly in the graph that the HVL and TVL values change depending on the gamma energy. The graph indicates that the HVL and TVL functions have different photon interactions in different energy regions. The curves of the HVL and TVL graph for all glasses varies coherently with each other in the $10^{-3}$ and $10^{-5} \mathrm{MeV}$ energy range as seen in Figure 4 and Figure 5. However, it can be seen that the change of HVL and TVL values in the low energy region remains nearly fixed depending on the photon energy. The HVL and TVL values are directly affected by the changes in the Si and Na doped ratios in the radiation protection glass, as seen in Figures 4 and 5. HVL and TVL values change to ISG-A12> ISG-A00N> ISG-A22> ISG-A23N>ISG-A00>ISG-A18N>ISG-A11N>ISG-C in ascending order. It was observed that ISG-A12 glasses took the highest HVL and TVL values, while ISG-C glasses took the lowest HVL and TVL value. Furthermore, the ISG-C glass which has the lowest value was observed that the reference/control glasses radiation protection feature. The obtained MFP, HVL, and TVL values were observed that they change in coherence with each other. From this aspect, it can be expressed that the 
MAC calculations are related to the HVL, TVL, and MFP calculations for photon effects in the different energy values.

\section{3. $Z_{\text {eff, }} \mathbf{N}_{\text {eff }}$ and $\mathbf{C}_{\text {eff }}$}

One of the important parameters calculated in nuclear studies and materials science is the effective atomic number $\left(Z_{\text {eff }}\right)$. $Z_{\text {eff }}$ is the value of the average atomic number for compounds or mixtures. The studies we have conducted to study the gamma radiation shielding features of glass samples are very important to calculate the $Z_{\text {eff }}$ value. When we have a material with a high $Z_{\text {eff }}$ value, the more photons in the target would collide with the atoms in the material, and therefore the interaction rate of photons with the material could be higher. Accordingly, the determination of the properties for shielding of compounds with high $Z_{\text {eff }}$ values by looking at the gamma photon interactions is very substantial in practical applications $[25,26]$. As seen in our example of compounds containing the elements $\mathrm{Si}, \mathrm{O}, \mathrm{Al}$, $\mathrm{B}, \mathrm{Na}, \mathrm{Ca}$, and $\mathrm{Zr}$ it is crucial to determine the $\mathrm{Z}_{\mathrm{eff}}$ value to indicate the attenuation of the material in other compounds as well. Therefore, the change of $Z_{\text {eff }}$ values depends on the properties of the element. As the ratio of the element in the compound which has the highest atomic number raises, the $\mathrm{Z}_{\mathrm{eff}}$ value rises as well. The $Z_{\text {eff }}$ value for photon interactions can be calculated by the steps as in the following. The $\sigma a$ computation can be applied to the formula, investigating the total atomic cross-section, as follows:

$$
\sigma_{a}=\frac{\mu / \rho}{N_{A} \sum_{i} \frac{w_{i}}{A_{i}}}
$$

$\sigma e$ indicates the total electronic cross-section and the computation can be performed by the given equation as follows:

$$
\sigma_{e}=\frac{1}{N_{A}} \sum_{i}\left(\sum_{j} \frac{f_{j} A_{j}}{A_{j}}\right) w_{i}
$$

The $\mathrm{Z}_{\text {eff }}$ value can be computed for glasses that have many components as follows: 


$$
Z_{e f f}=\frac{\sigma_{a}}{\sigma_{e}}
$$

$$
Z_{e f f}=\frac{\sum_{i} f_{i} A_{i}\left(\mu_{\rho}\right)_{i}}{\sum_{j} f_{j} \frac{A_{j}}{Z_{j}}\left(\mu_{\rho}\right)_{j}}
$$

where $f_{i}=n_{i} / \sum_{j} n_{j}$ states the fractional abundance, $Z_{j}$ which means the number of atoms of main elements and $\mathrm{N}_{\mathrm{A}}$ is known as the Avogadro constant. As seen the change of the Zeff value is subject to the energy. The $Z_{\text {eff }}$ values computed for the glassy samples in this research are given in Figure 6. As seen in Figure 6, the materials with the highest $Z_{\text {eff }}$ values are also quite high in photon attenuation. In Figure 6., it can be seen that the $Z_{\text {eff }}$ value changes as a function of the photon energy. In this research, ISG-A00N was determined as the best shielding material since the $\mathrm{Z}_{\text {eff }}$ has the highest value. Figure 6. indicates that the $\mathrm{Z}_{\text {eff }}$ value has peaked in the $0.01 \mathrm{MeV}$ to $0.1 \mathrm{MeV}$ energy range. As shown in Figure 6. that the $\mathrm{Z}_{\text {eff }}$ value decreases sharply from $0.286 \mathrm{MeV}$ to $0.826 \mathrm{MeV}$ and then the rate of decrease slows down. This change in the $Z_{\text {eff }}$ function indicates that the interaction of photons with the absorbing medium is directly related to energy. While the results of the photoelectric effects are very important for this interaction at first, this effect decreases sharply after the energy value of $\mathrm{E}^{-3.5}$. In addition, after the energy value of $0.826 \mathrm{MeV}$ in Figure 6., as seen that the $\mathrm{Z}_{\text {eff }}$ function remains approximately constant despite the energy increase.

The $\mathrm{N}_{\text {eff }}$ value, as in the $\mathrm{Z}_{\text {eff }}$ value, is used to define the effect of $\mathrm{X}$ - and gamma rays penetrating compounds containing many elements in their structure. The values of $Z_{\text {eff }}$ and $N_{\text {eff }}$ have been investigated in glasses and various materials conducting in many studies and the results have shown that these values have a similar tendency for change [27,28]. The following equality can be used when calculating $\mathrm{N}_{\mathrm{eff}}$ :

$$
N_{\text {eff }}=\frac{(\mu / \rho)_{c}}{\sigma_{e}}=\frac{N_{A}}{M} Z_{\text {eff }} \sum_{i} n_{i}(\text { electrons } / g)
$$


where $M$ symbolizes the mass of the particle and $n_{i}$ represents the whole number of atoms of the primary element. The graph of the $\mathrm{N}_{\text {eff }}$ values calculated for the glasses in this study is given in Figure 7. As seen in Figure 7., since the photon interaction mechanisms are similar in the studied energy range, thus, the change of the $\mathrm{N}_{\text {eff }}$ value is inverse with the $\mathrm{Z}_{\mathrm{eff}}$ value but compatible with it. In this study, the maximum $\mathrm{N}_{\text {eff }}$ value was found for the ISG-A23N glass sample and the $\mathrm{N}_{\text {eff }}$ values are given in descending order as ISG-C>ISG-A00> ISG-A12> ISG-A22>ISg-A00N>ISG-AA11N>ISG-A18N> ISG-A23N.

Effective conductivity $\left(\mathrm{C}_{\text {eff; }} \mathrm{S} / \mathrm{m}\right)$ provides the calculation of the Neff ratio directly, and the value of $\mathrm{C}_{\mathrm{eff}}$ can be calculated by using the formula given in the following [7];

$c_{e f f}=\left(\frac{N_{e f f} \rho e^{2} \tau}{m_{e}}\right) 10^{3}$

where $e(\mathrm{C})$ and $m_{e}(\mathrm{~kg})$ are quantities representing the charge of the electron and the mass of the electron. $\tau$ (s) gives the relaxation time of the electron on the Fermi surface and can be calculated by the formula in the following [29];

$\tau=\frac{\hbar}{k_{B} T}=\frac{h}{2 \pi k_{B} T}$

where $h$ (J.s) is Planck constant, $\mathrm{k}_{\mathrm{B}}(\mathrm{J} / \mathrm{K})$ is Boltzman constant and $\mathrm{T}(\mathrm{K})$ is the temperature of the environment. As shown in Figure 8., the graph of $\mathrm{C}_{\mathrm{eff}}$ values is given. The $\mathrm{Ce}_{\mathrm{ff}}$ value is a radiation protection parameter that offers a great opportunity to determine the material with the best shielding feature as in the MAC, HVL, TVL, MFP, $Z_{\text {eff }}$ and $N_{\text {eff }}$ values. The highest $\mathrm{C}_{\text {eff }}$ value was found for the ISG-A23N glass sample.

\subsection{Zeq, EBF and EABF}

In addition to the calculation methods given above, the geometric progression (G-P) fitting parameters were also computed by means of the Phy-X / PSD software which was developed by Harima. G-P fitting parameters were received from the ANSI / ANS-6.4.3 standard reference database which was used for 
the analysis of elements [30]. The build-up factor refers to the ratio of the amount of radiation scattered at a given location and the amount of radiation without interrupting at that location (i.e., as a function of a mean free path). Determination of exposure build-up factor (EBF) is a very important parameter that is used in radiation shielding studies. It is possible to examine the values either as EBF or energy absorption build-up factor (EABF). The calculation of EBF and EABF values is appropriate for gamma photon interactions. In this study, EBF and EABF values were calculated for 1, 2, 3, 4, 5, 6, 7, 8, 10 and $15 \mathrm{mfp}$ values between $0.015 \mathrm{MeV}$ and $15 \mathrm{MeV}$. Therefore, G-P fitting parameters are calculated by using the interpolation method as in the obtaining of the equivalent atomic number (Zeq). Total build up values are obtained by the steps in the following order. As a first step, for Zeq interpolation, Compton partial mass attenuation coefficient $(\mu / \rho)_{\text {Compton }}$ and total mass attenuation coefficient $(\mu / \rho)_{\text {Total }}$ is determined to calculate for the glass components in the study [31,32]. The following equation can be used to calculate Zeq;

$Z_{e q}=\frac{Z_{1}\left(\log R_{2}-\log R\right)+Z_{2}\left(\log R-\log R_{1}\right)}{\log R_{2}-\log R_{1}}$

where, in the equation given above $\mathrm{R}_{1}$ and $\mathrm{R}_{2}$ values denotes the $(\mu / \rho)_{\text {Compton }} /(\mu / \rho)_{\text {Total }}$, proportions of these two adjacent elements which have $Z_{1}$ and $Z_{2}$ are the atomic numbers. $R$ indicates the proportion of glasses studied in a particular energy [33].

After this, G-P fitting parameters are used to evaluate the Photon build-up factors (a, b, c, d, $\mathrm{X}_{\mathrm{K}}$ ). The logarithmic interpolation operations are performed as it is with the Zeq. The values of these five variables change according to Zeq value and energy [34]. The specified fitting parameters can be calculated using the following equation.

$P=\frac{P_{1}\left(\log Z_{2}-\log Z_{e q}\right)+P_{2}\left(\log Z_{e q}-\log Z_{1}\right)}{\log Z_{2}-\log Z_{1}}$

wherein the P-value for the material which is investigated $\left(\mathrm{a}, \mathrm{b}, \mathrm{c}, \mathrm{d}, \mathrm{X}_{\mathrm{K}}\right)$ is known as the G-P fitting parameters. On the other side, the $\mathrm{P}_{1}$ and $\mathrm{P}_{2}$ values show the G-P fitting parameters corresponding to atomic numbers $Z_{1}$ and $Z_{2}$, which are obtained from the ANSI database [30].

As a result, 


$$
\begin{array}{ll}
B(E, X)=1+\left(\frac{b-1}{K-1}\right)\left(K^{x}-1\right) & \text { for } K \neq 1 \\
B(E, X)=1+(b-1) x & \text { for } K=1
\end{array}
$$

where, $\mathrm{E}$ is the photon energy and $\mathrm{X}$ is the penetration depth. For the glasses which are given in this study, the $\mathrm{X}$ values were calculated between 0.5 and 40 MFPs $[35,36]$.

$$
K(E, x)=\left(c x^{a}+d\right) \frac{\tanh \left(\frac{x}{X_{K}}-2\right)-\tanh (-2)}{1-\tanh (-2)} \quad \text { for } x \leq 40 \mathrm{mfp}
$$

The shape of the spectrum can be determined by looking at the multi-photon dose combination which is made with the $\mathrm{K}(\mathrm{E}, \mathrm{X})$ function. Calculations were made by taking into account the photons colliding inside and outside and remaining without collision as a result of the interaction of gamma radiation with the material. Figure 10. and Figure 11. are the graphs of EBF, EABF. G-P fitting coefficients and Zeq values for the ISC-A23N glass sample are given in Figure 9. The graphs of the EBF and EABF values calculated for low-medium and high energy regions for the selected glass samples are given in Figure 10. and Figure 11. Referring to the graphs, the maximum build-up factor can be seen at the ISG-A23N glass due to an increase in the Compton scattering (CS). Therefore, as seen that the CS and EBF and EABF values change proportionally. The build-up factors grew with increasing depth of penetration as the increase in glass thickness indicates more secondary photons. ISG-A23N glass has been found the highest value of the EBF-EABF calculations for the given glasses and it has been observed that this value varies inversely with the $Z_{\text {eq }}$ value. In the same way, ISG-A00N glass has been found the lowest value of the EBF-EABF calculations for the given glasses and it has been observed that this value varies inversely with the $Z_{\text {eq }}$ value. In Figure 10. and Figure 11., EBF and EABF values change similarly in terms of the mathematical functions to each other. As clearly seen that the EBF and EABF values of the best shielding material in ISG-A23N are at $0.1 \mathrm{MeV}$ energy.

\subsection{FNRCS $(\Sigma R)$}

In addition to all these, also Fast Neutron-Removal Cross-Section (FNRCS) calculations were made to measure the interactions of neutrons. Neutrons are uncharged particles, and indeed, when investigating 
the radiation shielding effect of the material, it is also needed to consider the effects of neutrons. The FNRCS indicates a measure of the rate of initial penetration of un-collided neutrons [7,37]. FNRCS is a method to understand the effect of radiation on the material which is examined for shielding feature while some nucleus interactions and scattering. The FNRCS value can be calculated for different thicknesses using Beer-Lambert law for elements, compounds and mixtures. The basic processes of FNRCS consist of such as elastic and inelastic scattering, nuclear fission, and neutron capture. The fast neutron effective removal cross-section value is computed for $\Sigma \mathrm{R}\left(\mathrm{cm}^{-1}\right)$ or $\Sigma \mathrm{R} / \rho\left(\mathrm{cm}^{2} \mathrm{~g}^{-1}\right)$ for each element / composition;

$\sum_{R} / \rho=\sum_{i} W_{i}(\Sigma R / \rho)_{i}$

and

$\sum_{R}=\sum_{i} \rho_{i}(\Sigma R / \rho)_{i}$

where wi represents the weight percentages of glass compounds. $\rho$ i is the density of the glass compound, and $\left(\sum \mathrm{R} / \rho\right)_{\mathrm{i}} \mathrm{i}$ is the neutron reduction cross-section of the compound. In the following, the formula states the obtaining of the $\Sigma \mathrm{R}\left(\mathrm{cm}^{-1}\right)$ value.

$\sum R=\sum W_{i}\left(\sum R / \rho\right)_{i}$

where the weight percentage is symbolized by wi $\left(\mathrm{g} / \mathrm{cm}^{3}\right)$ and the mass removal cross-section of the $\mathrm{i}^{\text {th }}$ element is indicated by $\Sigma \mathrm{R} / \rho\left(\mathrm{cm}^{2} / \mathrm{g}\right)$.

The $\Sigma \mathrm{R}$ values for the glass materials used in this study were calculated by using the Phy-X-PSD code. The graphic of the calculated values can be seen in Figure 12. As seen clearly in the graph that the ISG$\mathrm{C}$ has the highest $\Sigma \mathrm{R}$ value and ISG-A23N has the lowest $\Sigma \mathrm{R}$ value. This situation can be explained as follows:

the density of the glass material can affect the result while calculating the $\Sigma \mathrm{R}$ values of the glasses that can be seen clearly in Figure 12. Furthermore, there was an increase in $\Sigma R$ values depending on the increase in the density of glass material (Table 1). 


\section{6. $\mathrm{MSP}\left(\mathrm{H}^{1}\right.$ and $\left.\mathrm{He}^{+2}\right), \operatorname{PR}\left(\mathrm{H}^{1}\right.$ and $\left.\mathrm{He}^{+2}\right)$}

Finally, it has been aimed to investigate the pass-through of the charged particles by using Monte Carlo based SRIM code in this study. SRIM calculations are a very powerful analysis method that is used to measure the amount of radiation damage on the material. Actually, this method aims to calculate the damage to the material due to radiation. In the calculation of $\operatorname{MSP}\left(\mathrm{MeVcm}^{2} / \mathrm{g}\right)$, it can be seen that the amount of radiation impacting the material is affected by the energy change [38]. Therefore, SRIM is preferred since it is software that measures the amount of radiation effect related to energy. The results obtained from SRIM are used to measure the effect of ions on the material, in other words, to determine the damage caused by the radiation to the material. In the SRIM code, the particle distribution is obtained by normalization since the particles' positions stay stable. The MAC value changes in direct proportion to $\mathrm{Z}$, and this causes an increase in the MSP value [11,39]. The following equation can be used for the MSP values calculated using the Bethe-Bloch formula;

$$
-\frac{d E}{d x}=\frac{4 \pi k_{0}^{2} Z^{2} e^{4} n}{m c^{2} \beta^{2}}\left[\ln \frac{2 m c^{2} \beta^{2}}{I\left(1-\beta^{2}\right)}-\beta^{2}\right]
$$

in the given MSP formula, the following notations have been used as: for the mass (m), the density of the glass $(\rho)$, the charge (e), the velocity $(\beta)$ of the ion, and the atomic number (Z) [38]. As a result of the interaction of charged particles with atomic electrons in the material, electronic stopping power occurs and the interaction of charged particles with the nucleus of the atom, nuclear stopping power occurs. The results which are obtained from MSP can be used to explain the durability of the material in terms of radiation protection $[9,28]$.

The projected range (PR), $\mathrm{g}\left(\mathrm{cm}^{-2}\right)$ is a parameter used to determine the number of particles that penetrate increasing thicknesses of the material. The PR of the charged particle can be defined as the distance which it took before resting. However, it does not mean the stopping power of the energy divided is equal to the PR. The same calculations can be applied for all materials with similar atomic components in the calculation of the PR values as in the calculation of MSP values. The material with the lowest PR 
value indicates that this material has the best protective feature. PR value is calculated as in the following equation $[10,22,40]$;

$$
R(\beta)=\left(M / Z^{2}\right) R_{p}(\beta)
$$

In this investigation, MSP and PR values were computed for the energy range between $0.15 \mathrm{MeV}$ and $20 \mathrm{MeV}$ using ISG-C, ISG-A00, ISG-A12, ISG-A22, ISG-A00N, ISG-AA11N, ISG-A18N and ISGA23N glasses. As seen in the graphics; $\mathrm{H}^{1}$ and $\mathrm{He}^{+2}$ particles are affected by the change of kinetic energy. It can be seen that the PR value which was calculated for ISG-A23N glass was greater than the PR value for ISG-A00. Therefore, for that particular photon energy, this result is coherent with the smaller MSP values of ISG-A23N. Similar cases are valid for the MSP curves of alpha particles for the same glasses. Since the proton $\left(\mathrm{H}^{1}\right)$ is lighter than the alpha $\left(\mathrm{He}^{+2}\right)$ particle, the energy loss due to the collision occurs more fast in the orbit. For that reason, in lower energy regions, the MSP $\left(\mathrm{H}^{1}\right)$ value reached a higher value than MSP $\left(\mathrm{He}^{+2}\right)$. The values for MSP $\left(\mathrm{H}^{1}\right)$ are given in descending order: ISG-C, ISG-A00, ISGA12, ISG-A22, ISG-A00N, ISG-AA11N, ISG-A18N and ISG-A23N respectively. The lowest MSP $\left(\mathrm{H}^{1}\right)$ value was obtained in ISG-A23N glass and the highest value was obtained at 0.1 and $0.8 \mathrm{MeV}$ energy values in ISG-A00N glass. Thus, the MSP curve, which takes its maximum value had a sharp decrease due to the increase in energy. Likewise, this situation was observed also for the same glasses and for $\operatorname{MSP}\left(\mathrm{He}^{+2}\right)$ in these energies 0.5 and $0.9 \mathrm{MeV}$ in Figure 13. and 14. The highest MSP values $\left(\mathrm{H}^{1}\right.$ and $\mathrm{He}^{+2}$ ) were observed in ISG-A00N glasses which have a high Si ratio.

Since the particles do not follow a linear path during the interaction with the material, it cannot be determined the distance they take precisely. Therefore, PR values can be calculated to determine at which distance the particles are standing still. In this study, the $\mathrm{PR}\left(\mathrm{H}^{1}\right.$ and $\left.\mathrm{He}^{+2}\right)$ values were calculated for the given glasses and the results as seen in Figure 15. and 16., respectively. As seen in the PR graph the values actually change as a function of kinetic energy. $\mathrm{PR}\left(\mathrm{H}^{1}\right.$ and $\left.\mathrm{He}^{+2}\right)$ values calculated for glasses increased depending on the increase in kinetic energy. As it has been found that among all glasses, ISGA00N takes the longest path for PR $\left(\mathrm{H}^{1}\right.$ and $\left.\mathrm{He}^{+2}\right)$. In Figure 15. and 16., ISG-A00N glasses were also 
found the lowest value. It can be concluded that the glass with the best radiation protection performance is ISG-A00N glasses in accordance with the results of all SRIM calculations.

\section{Conclusion}

In this investigation, it has been aimed to contribute to the radiation protection studies of ISG-C, ISGA00, ISG-A12, ISG-A22, ISG-A00N, ISG-AA11N, ISG-A18N, and ISG-A23N glasses by using online Phy-X / PSD software. This program provides users with great ease of use which examines the interactions of gamma rays, charged particles, and neutrons. The $\mu / \rho, \mathrm{HVL}, \mathrm{TVL}, \mathrm{MFP}, \mathrm{Z}_{\mathrm{eff}}, \mathrm{N}_{\mathrm{eff}}$ and $\mathrm{C}_{\text {eff }}$ values were calculated for the $1 \mathrm{keV}-100 \mathrm{GeV}$ energy range by using this user-friendly software. $1,748,480$ numbers of calculations were computed by the Phy-X / PSD program with an excellent performance capacity in $894.07 \mathrm{sec}$. Additionally, measurements were also made in the characteristic $\mathrm{X}$-ray energy ranges of some well-known radioactive sources $\left({ }^{60} \mathrm{Co}\right.$ and $\left.{ }^{137} \mathrm{Cs}\right)$. Moreover, EBF-EABF and FNRCS values were calculated as well by using this software for selected glasses. Since the software offers users the opportunity to perform parallel processing ability, it is advantageous for them in terms of saving time. In addition to all these, $\mathrm{MSP}\left(\mathrm{H}^{1}\right.$ and $\left.\mathrm{He}^{+2}\right)$ and $\mathrm{PR}\left(\mathrm{H}^{1}\right.$ and $\left.\mathrm{He}^{+2}\right)$ values were calculated using SRIM codes in the energy range of $0.1-20 \mathrm{MeV}$ for the given glasses. The results of this study revealed that:

i. MAC value was affected by the increase and decrease of the ratio $\mathrm{Si}, \mathrm{Al}, \mathrm{B}, \mathrm{Na}, \mathrm{Ca}$, and $\mathrm{Zr}$ elements' in the glass content. It was observed that the MAC values for 8 different glasses obtained using different ratios decreased down to $0.5-0.7 \mathrm{MeV}$ energy range.

ii. Comparing the HVL, TVL and MFP values of all glass samples, it has been seen that ISG-A00N glasses take the lowest value. It has been found that these values change from 2.8 to $4.01 \mathrm{~cm}$, from 9.6 to $13.39 \mathrm{~cm}$, and from 2.74 to $3.74 \mathrm{~cm}$ in the $0.5-6 \mathrm{MeV}$ energy range, respectively.

iii. The Zeff value increased due to the increase of $\mathrm{Z}$ for ISG-A00N glasses (since the $\mathrm{Z}$ atomic number is the largest for this glass). Also, the Neff values changed inversely depending on the Zeff values. 
iv. EBF and EABF values have been calculated for different MFPs and it has been observed that the ISG-A23N glass have the highest value and the ISG-A00N glass have the lowest value.

v. From the point of view of the neutrons, it has been found ISG-A012 glasses had the highest value while ISG-A12N glass had the lowest value in FNRCS results.

vi. Considering the calculations of MSP and PR $\left(\mathrm{H}^{1}\right.$ and $\left.\mathrm{He}^{+2}\right)$ in the SRIM code, it was observed that the ISG-A23N glasses had the lowest MSP values while ISG-A00N glasses had the highest MSP values. Moreover, it was seen that the ISG-A23N glasses had the lowest PR of value and the ISG-A00N glasses had the highest PR value.

It has been seen that the ISG-A00N was confirmed as the most effective shielding glasses for the $\mu / \rho$, HVL, TVL, MFP, $\mathrm{Z}_{\mathrm{eff}}, \mathrm{N}_{\mathrm{eff}}$ and $\mathrm{C}_{\text {eff }}$ EBF, EABF, FNRCS, MSP $\left(\mathrm{H}^{1}\right.$ and $\left.\mathrm{He}^{+2}\right)$ and $\mathrm{PR}\left(\mathrm{H}^{1}\right.$ and $\left.\mathrm{He}^{+2}\right)$ values which have been calculated for the selected energy zone. In the light of all these results, it was determined that the best radiation shielding performance belongs to ISG-A00N glasses which was affected by the increase in $\mathrm{Al}:(\mathrm{Na}+\mathrm{Si})$ contribution. A result that is clearly visible the glasses with the larger density has a larger shielding capability.

Conflict of Interest: There is no conflict of interest.

\section{Acknowledgement: None.}

Appendix A. Supplementary data: https://doi.org/10.1111/jace.17447

\section{References}

[1] M. Collin, M. Fournier, P. Frugier, T. Charpentier, M. Moskura, L. Deng, M. Ren, J. Du, S. Gin, Structure of International Simple Glass and properties of passivating layer formed in circumneutral pH conditions, Npj Mater. Degrad. 2 (2018) 1-12. https://doi.org/10.1038/s41529017-0025-y.

[2] T.C. Kaspar, J. V. Ryan, C.G. Pantano, J. Rice, C. Trivelpiece, N.C. Hyatt, C.L. Corkhill, C. Mann, R.J. Hand, M.A. Kirkham, C.L. Crawford, C.M. Jantzen, J. Du, X. Lu, M.T. Harrison, C. Cushman, M.R. Linford, N.J. Smith, Physical and optical properties of the International Simple Glass, Npj Mater. Degrad. 3 (2019). https://doi.org/10.1038/s41529-019-0069-2.

[3] M. Debure, L. De Windt, P. Frugier, S. Gin, P. Vieillard, Mineralogy and thermodynamic properties of magnesium phyllosilicates formed during the alteration of a simplified nuclear glass, J. Nucl. Mater. 475 (2016) 255-265. https://doi.org/10.1016/j.jnucmat.2016.04.008.

[4] J.T. Reiser, X. Lu, B. Parruzot, H. Liu, T. Subramani, H. Kaya, R.M. Kissinger, J. V. Crum, J. V. Ryan, A. Navrotsky, S.H. Kim, J.D. Vienna, Effects of Al:Si and (Al + Na):Si ratios on the 
properties of the international simple glass, part I: Physical properties, J. Am. Ceram. Soc. 104 (2021) 167-182. https://doi.org/10.1111/jace.17449.

[5] X. Lu, J.T. Reiser, B. Parruzot, L. Deng, I.M. Gussev, J.C. Neuefeind, T.R. Graham, H. Liu, J. V. Ryan, S.H. Kim, N. Washton, M. Lang, J. Du, J.D. Vienna, Effects of Al:Si and (Al + Na):Si ratios on the properties of the international simple glass, part II: Structure, J. Am. Ceram. Soc. 104 (2021) 183-207. https://doi.org/10.1111/jace.17447.

[6] X. Lu, M. Ren, L. Deng, C.J. Benmore, J. Du, Structural features of ISG borosilicate nuclear waste glasses revealed from high-energy X-ray diffraction and molecular dynamics simulations, J. Nucl. Mater. 515 (2019) 284-293. https://doi.org/10.1016/j.jnucmat.2018.12.041.

[7] E. Şakar, Ö.F. Özpolat, B. Alım, M.I. Sayyed, M. Kurudirek, Phy-X / PSD: Development of a user friendly online software for calculation of parameters relevant to radiation shielding and $\begin{array}{llllll}\text { dosimetry, } & \text { Radiat. } & \text { Phys. } & \text { Chem. } & 166 & \text { (2020). }\end{array}$ https://doi.org/10.1016/j.radphyschem.2019.108496.

[8] A.M. Abu El-Soad, M.I. Sayyed, K.A. Mahmoud, E. Şakar, E.G. Kovaleva, Simulation studies for gamma ray shielding properties of Halloysite nanotubes using MCNP-5 code, Appl. Radiat. Isot. 154 (2019) 1-6. https://doi.org/10.1016/j.apradiso.2019.108882.

[9] J.F. Ziegler, Srim-2003, Nucl. Instruments Methods Phys. Res. Sect. B Beam Interact. with Mater. Atoms. 219-220 (2004) 1027-1036. https://doi.org/10.1016/j.nimb.2004.01.208.

[10] V. Kuzmin, Range parameters of heavy ions in carbon calculated with first-principles potentials, Nucl. Instruments Methods Phys. Res. Sect. B Beam Interact. with Mater. Atoms. 249 (2006) 13-17. https://doi.org/10.1016/j.nimb.2006.03.012.

[11] J.F. Ziegler, M.D. Ziegler, J.P. Biersack, SRIM - The stopping and range of ions in matter (2010), Nucl. Instruments Methods Phys. Res. Sect. B Beam Interact. with Mater. Atoms. 268 (2010) 1818-1823. https://doi.org/10.1016/j.nimb.2010.02.091.

[12] M. Guerette, L. Huang, In-situ Raman and Brillouin light scattering study of the international simple glass in response to temperature and pressure, J. Non. Cryst. Solids. 411 (2015) 101-105. https://doi.org/10.1016/j.jnoncrysol.2014.12.028.

[13] X. Lu, R. Sun, L. Huang, J. V. Ryan, J.D. Vienna, J. Du, Effect of vanadium oxide addition on thermomechanical behaviors of borosilicate glasses: Toward development of high crack resistant glasses for nuclear waste disposal, J. Non. Cryst. Solids. 515 (2019) 88-97. https://doi.org/10.1016/j.jnoncrysol.2019.04.009.

[14] S. Mohd Fadzil, P. Hrma, M.J. Schweiger, B.J. Riley, Liquidus temperature and chemical durability of selected glasses to immobilize rare earth oxides waste, J. Nucl. Mater. 465 (2015) 657-663. https://doi.org/10.1016/j.jnucmat.2015.06.050.

[15] A. Asskın, Evaluation of the radiation shielding capabilities of the Na2B4O7-SiO2-MoO3Dy2O3 glass quaternary using Geant 4 simulation code and Phy-X/PSD database, Ceram. Int. 46 (2020) 9096-9102. https://doi.org/10.1016/j.ceramint.2019.12.158.

[16] Y. Al-Hadeethi, M.I. Sayyed, Using Phy-X/PSD to investigate gamma photons in SeO2-Ag2O$\mathrm{TeO} 2$ glass systems for shielding applications, Ceram. Int. 46 (2020) 12416-12421. https://doi.org/10.1016/j.ceramint.2020.02.003.

[17] Y.M. Aboudeif, M.S. Alqahtani, E.E. Massoud, I.S. Yaha, E. Yousef, An evaluation of the radiation protection characteristics of prototyped oxide glasses utilising Phy-X/PSD software, J. Instrum. 15 (2020). https://doi.org/10.1088/1748-0221/15/08/P08005.

[18] S.F. Olukotun, S.T. Gbenu, O.F. Oladejo, M.I. Sayyed, S.M. Tajudin, A.A. Amosun, O.G. Fadodun, M.K. Fasasi, Investigation of gamma ray shielding capability of fabricated claypolyethylene composites using EGS5, XCOM and Phy-X/PSD, Radiat. Phys. Chem. 177 (2020) 109079. https://doi.org/10.1016/j.radphyschem.2020.109079.

[19] S.A.M. Issa, M.I. Sayyed, A.M.A. Mostafa, G. Lakshminarayana, I. V. Kityk, Investigation of mechanical and radiation shielding features of heavy metal oxide based phosphate glasses for gamma radiation attenuation applications, J. Mater. Sci. Mater. Electron. 30 (2019) 1214012151. https://doi.org/10.1007/s10854-019-01572-x.

[20] K.M. Kaky, M.I. Sayyed, A.A. Ati, M.H.A. Mhareb, K.A. Mahmoud, S.O. Baki, M.A. Mahdi, Germanate oxide impacts on the optical and gamma radiation shielding properties of $\mathrm{TeO} 2-\mathrm{ZnO}-$ Li2O glass system, J. Non. Cryst. Solids. $546 \quad$ (2020) 120272. 
https://doi.org/10.1016/j.jnoncrysol.2020.120272.

[21] K.A. Mahmoud, M.I. Sayyed, O.L. Tashlykov, Comparative studies between the shielding parameters of concretes with different additive aggregates using MCNP-5 simulation code, Radiat. Phys. Chem. 165 (2019) 108426. https://doi.org/10.1016/j.radphyschem.2019.108426.

[22] M. Kamislioglu, Research on the effects of bismuth borate glass system on nuclear radiation $\begin{array}{llllll}\text { shielding parameters, } & \text { Results } & \text { Phys. } & 22 & \text { (2021) }\end{array}$ https://doi.org/10.1016/j.rinp.2021.103844.

[23] S.A.M. Issa, A. Kumar, M.I. Sayyed, M.G. Dong, Y. Elmahroug, Mechanical and gamma-ray shielding properties of TeO2-ZnO-NiO glasses, Mater. Chem. Phys. 212 (2018) 12-20. https://doi.org/10.1016/j.matchemphys.2018.01.058.

[24] M.I. Sayyed, A. Kumar, H.O. Tekin, R. Kaur, M. Singh, O. Agar, M.U. Khandaker, Evaluation of gamma-ray and neutron shielding features of heavy metals doped $\mathrm{Bi} 2 \mathrm{O} 3-\mathrm{BaO}-\mathrm{Na} 2 \mathrm{O}-\mathrm{MgO}-$ B2O3 glass systems, Prog. Nucl. Energy. 118 (2020) 103118. https://doi.org/10.1016/j.pnucene.2019.103118.

[25] S.A.M. Issa, Effective atomic number and mass attenuation coefficient of $\mathrm{PbO}-\mathrm{BaO}-\mathrm{B} 2 \mathrm{O} 3$ glass $\begin{array}{llllll}\text { system, } & \text { Radiat. } & \text { Phys. } & \text { Chem. } & \end{array}$ https://doi.org/10.1016/j.radphyschem.2015.11.025.

[26] J.E. Ngaile, C.B.S. Uiso, P. Msaki, R. Kazema, Use of lead shields for radiation protection of superficial organs in patients undergoing head CT examinations, Radiat. Prot. Dosimetry. 130 (2008) 490-498. https://doi.org/10.1093/rpd/ncn095.

[27] S. Gowda, S. Krishnaveni, T. Yashoda, T.K. Umesh, R. Gowda, Photon mass attenuation coefficients, effective atomic numbers and electron densities of some thermoluminescent dosimetric compounds, Pramana - J. Phys. 63 (2004) 529-541. https://doi.org/10.1007/BF02704481.

[28] M. Kamislioglu, E.E. Altunsoy Guclu, H.O. Tekin, Comparative evaluation of nuclear radiation shielding properties of $\mathrm{xTeO} 2+(100-\mathrm{x}) \mathrm{Li} 2 \mathrm{O}$ glass system, Appl. Phys. A Mater. Sci. Process. 126 (2020). https://doi.org/10.1007/s00339-020-3284-3.

[29] J.M. Ziman, Solid state, Phys. Today. 21 (1968) 53-58. https://doi.org/10.1063/1.3034969.

[30] M.J. and H. Trubey, D. K. Berger, Photon cross sections for endf/b-vi*, (2008).

[31] Y. Harima, Y. Sakamoto, S. Tanaka, M. Kawai, Validity of the Geometric-Progression Formula in Approximating Gamma-Ray Buildup Factors., Nucl. Sci. Eng. 94 (1986) 24-35. https://doi.org/10.13182/NSE86-A17113.

[32] L. Gerward, N. Guilbert, K. Bjorn Jensen, H. Levring, X-ray absorption in matter. Reengineering XCOM, Radiat. Phys. Chem. 60 (2001) 23-24. https://doi.org/10.1016/S0969-806X(00)003248.

[33] L. Gerward, N. Guilbert, K.B. Jensen, H. Levring, WinXCom - A program for calculating X-ray attenuation coefficients, Radiat. Phys. Chem. 71 (2004) 653-654. https://doi.org/10.1016/j.radphyschem.2004.04.040.

[34] P.S. Singh, T. Singh, P. Kaur, Variation of energy absorption buildup factors with incident photon energy and penetration depth for some commonly used solvents, Ann. Nucl. Energy. 35 (2008) 1093-1097. https://doi.org/10.1016/j.anucene.2007.10.007.

[35] Y. Harima, An historical review and current status of buildup factor calculations and applications, Radiat. Phys. Chem. 41 (1993) 631-672. https://doi.org/10.1016/0969806X(93)90317-N.

[36] B. Oto, A. Gür, E. Kavaz, T. Çakır, N. Yaltay, Determination of gamma and fast neutron shielding parameters of magnetite concretes, Prog. Nucl. Energy. 92 (2016) 71-80. https://doi.org/10.1016/j.pnucene.2016.06.011.

[37] C. All, A. Search, S. All, Search My Selection Search History $\square$, I (2020) 1-2.

[38] J.F. Ziegler, M.D. Ziegler, J.P. Biersack, SRIM - The stopping and range of ions in matter (2010), Nucl. Instruments Methods Phys. Res. Sect. B Beam Interact. with Mater. Atoms. 268 (2010) 1818-1823. https://doi.org/10.1016/j.nimb.2010.02.091.

[39] H.O. Tekin, E.E. Altunsoy, E. Kavaz, M.I. Sayyed, O. Agar, M. Kamislioglu, Photon and neutron shielding performance of boron phosphate glasses for diagnostic radiology facilities, Results Phys. 12 (2019) 1457-1464. https://doi.org/10.1016/j.rinp.2019.01.060. 
[40] E. Kavaz, F.I. El-Agawany, H.O. Tekin, U. Perişanoğlu, Y.S. Rammah, Nuclear radiation shielding using barium borosilicate glass ceramics, J. Phys. Chem. Solids. 142 (2020). https://doi.org/10.1016/j.jpcs.2020.109437. 
Figures

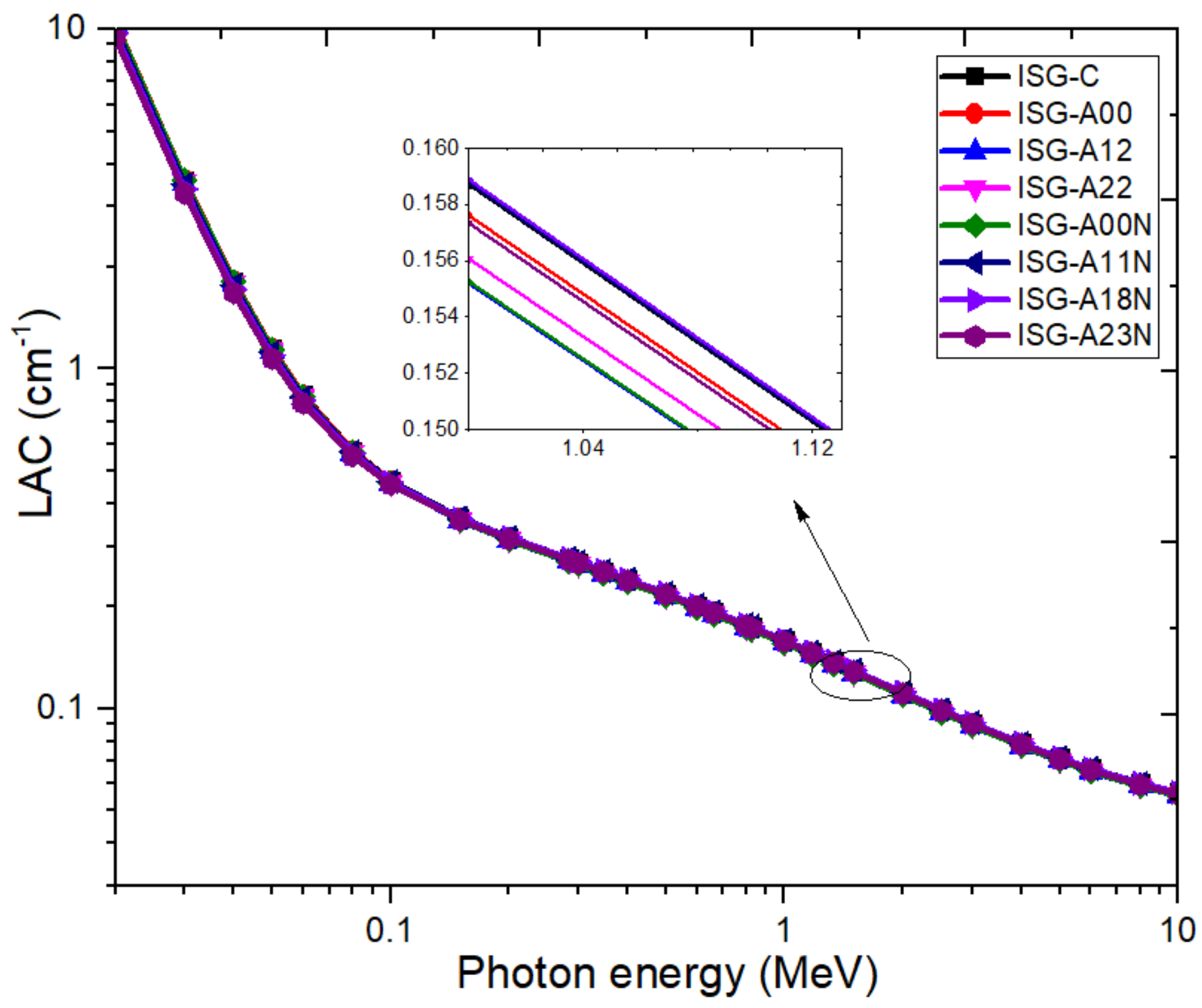

Figure 1

The linear attenuation coefficient for the investigated SiO2-Al2O3-B2O3-Na2O-CaO-ZrO2 glass systems 


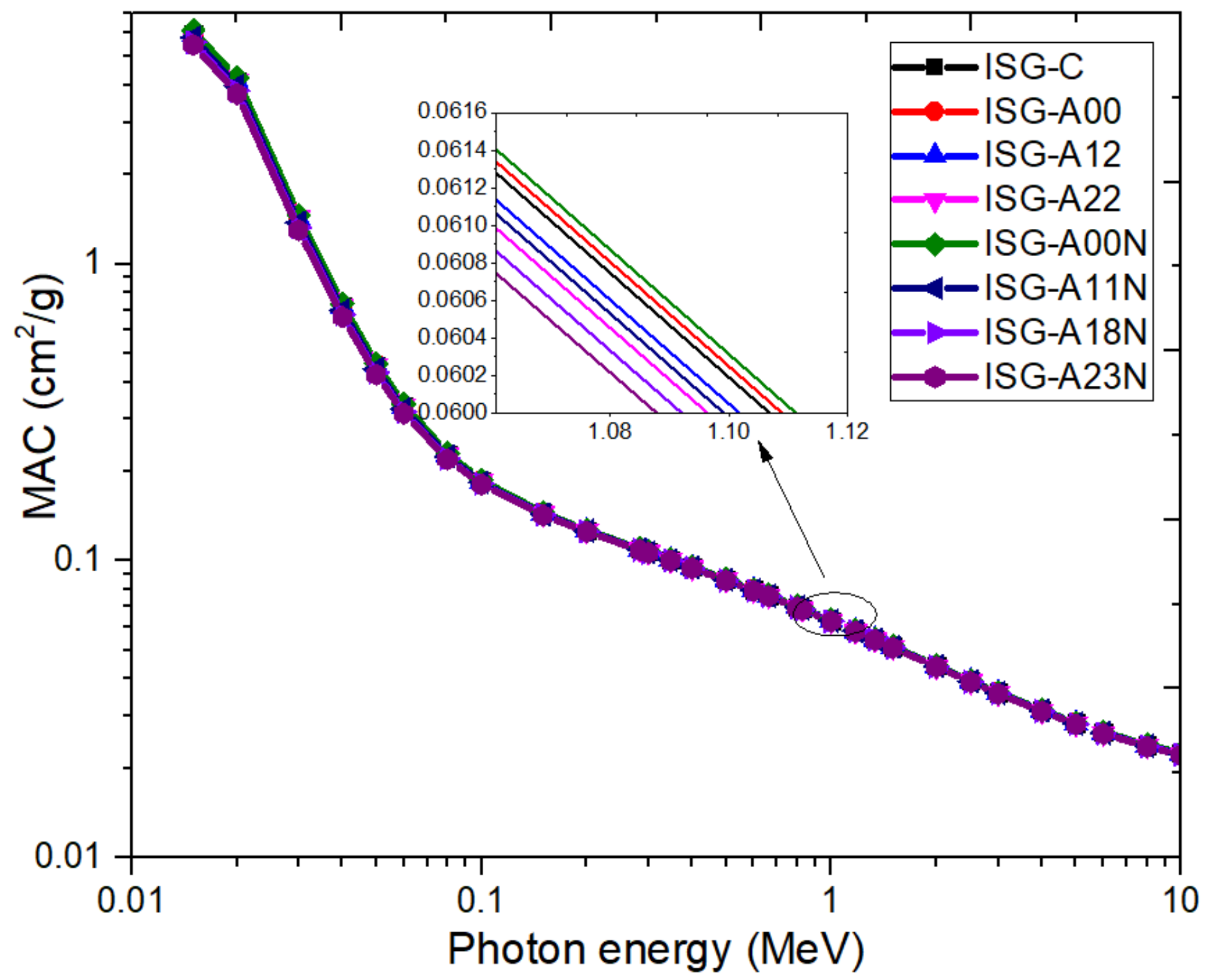

Figure 2

The mass attenuation coefficient for the investigated SiO2-Al2O3-B2O3-Na2O-CaO-ZrO2 glass systems 


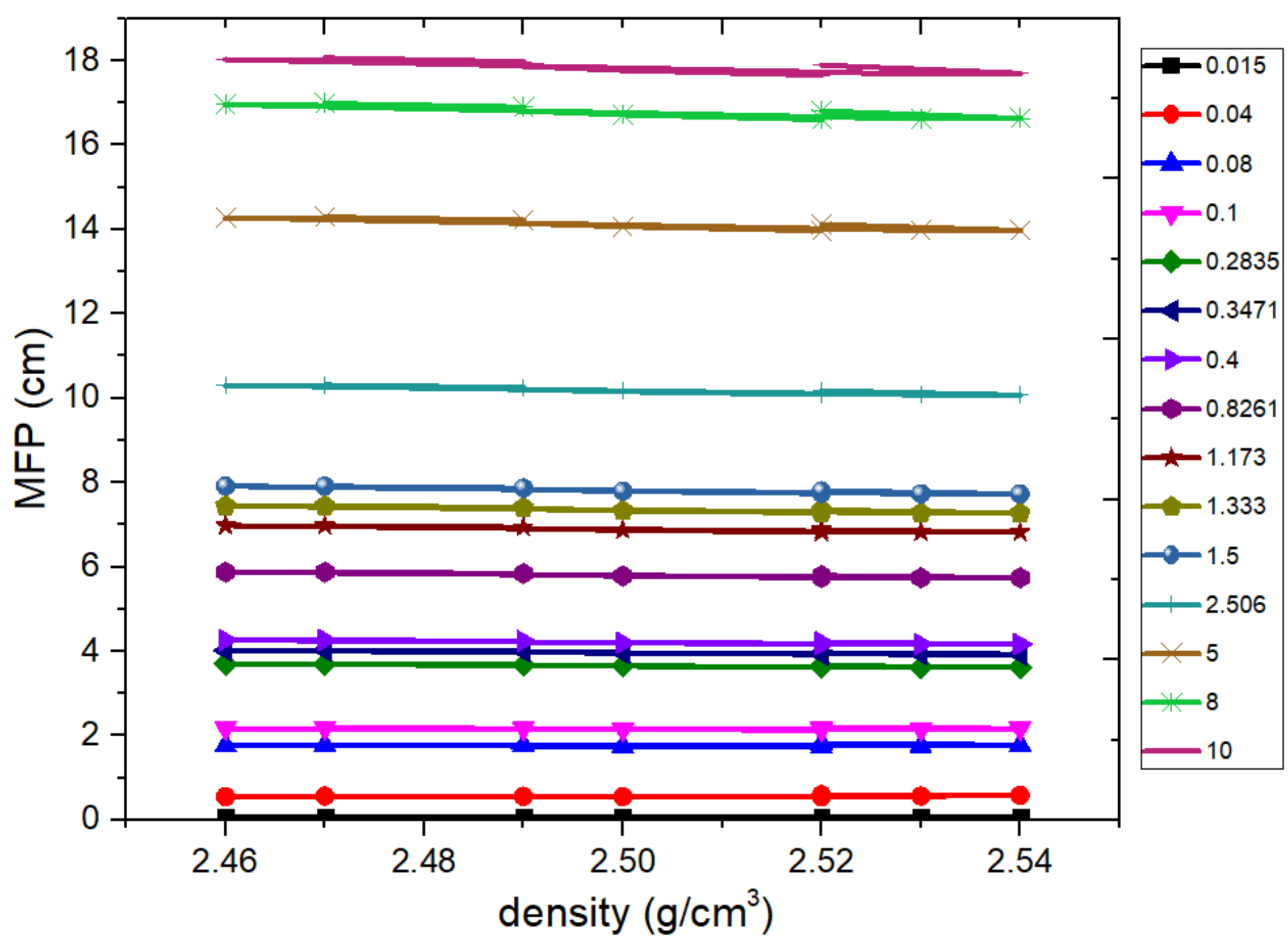

Figure 3

The mean free path for the investigated SiO2-Al2O3-B2O3-Na2O-CaO-ZrO2 glass systems as a function of the density 


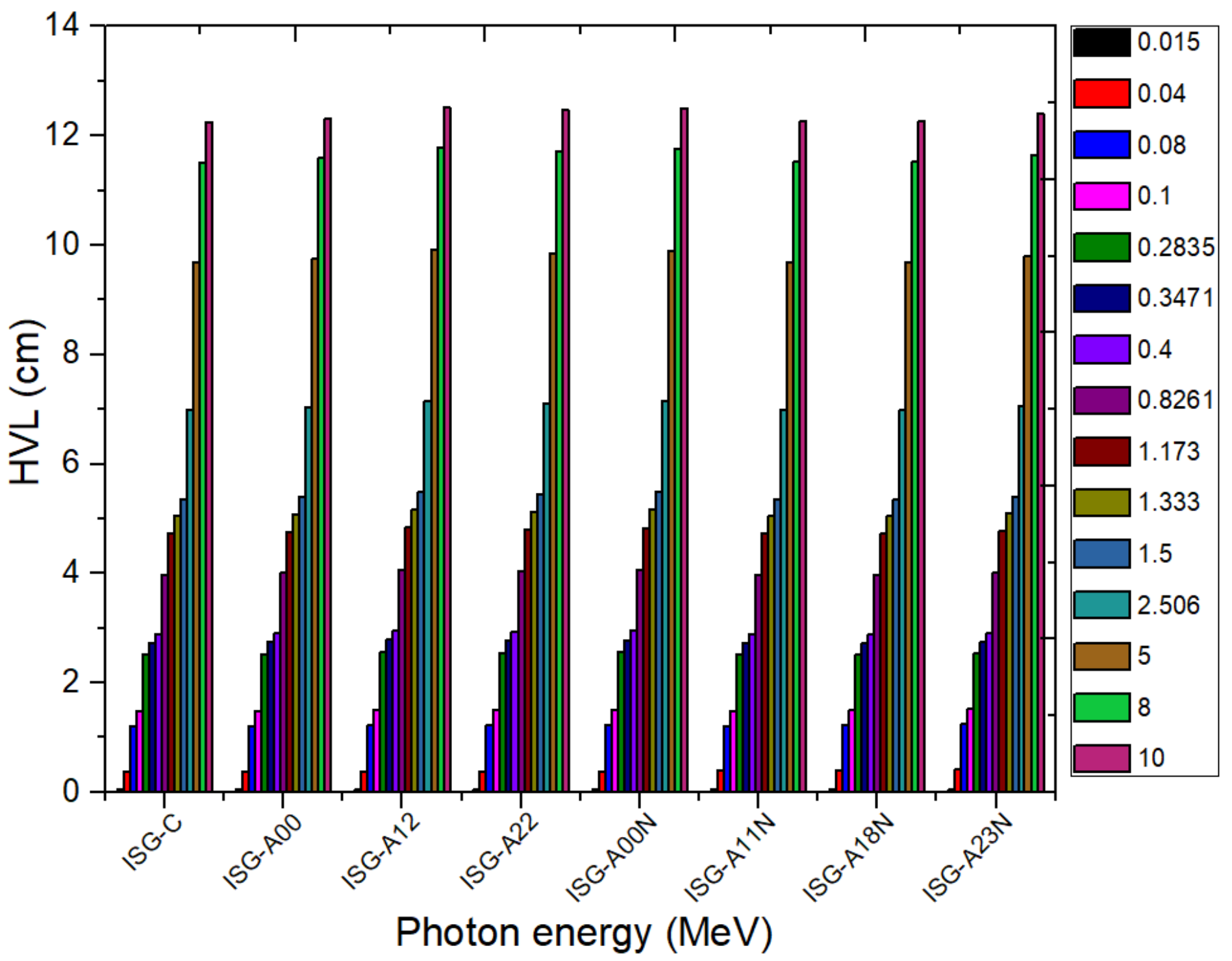

Figure 4

The half value layer for the investigated SiO2-Al2O3-B2O3-Na2O-CaO-ZrO2 glass systems 


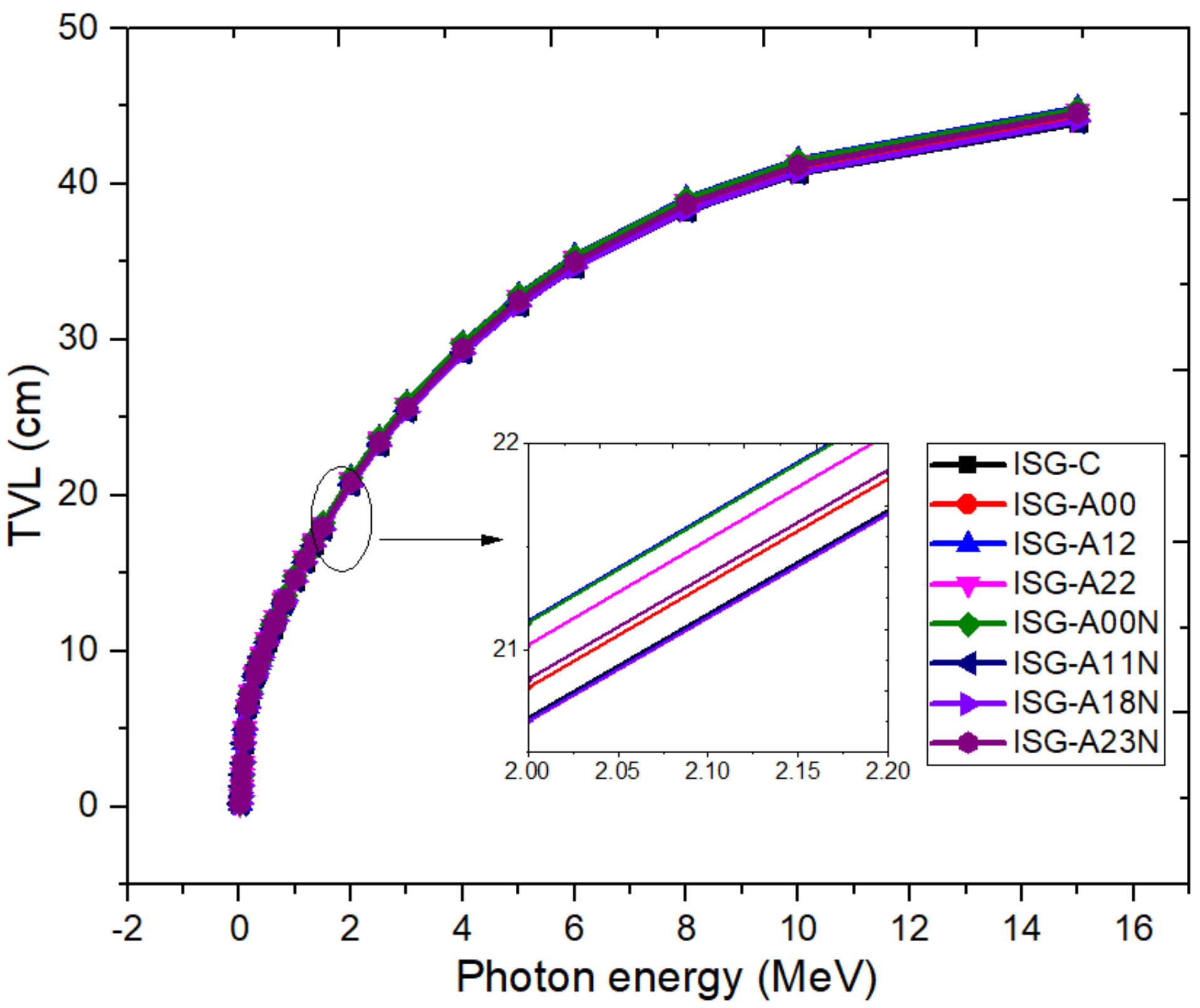

Figure 5

The tenth value layer for the investigated SiO2-Al2O3-B2O3-Na2O-CaO-ZrO2 glass systems 


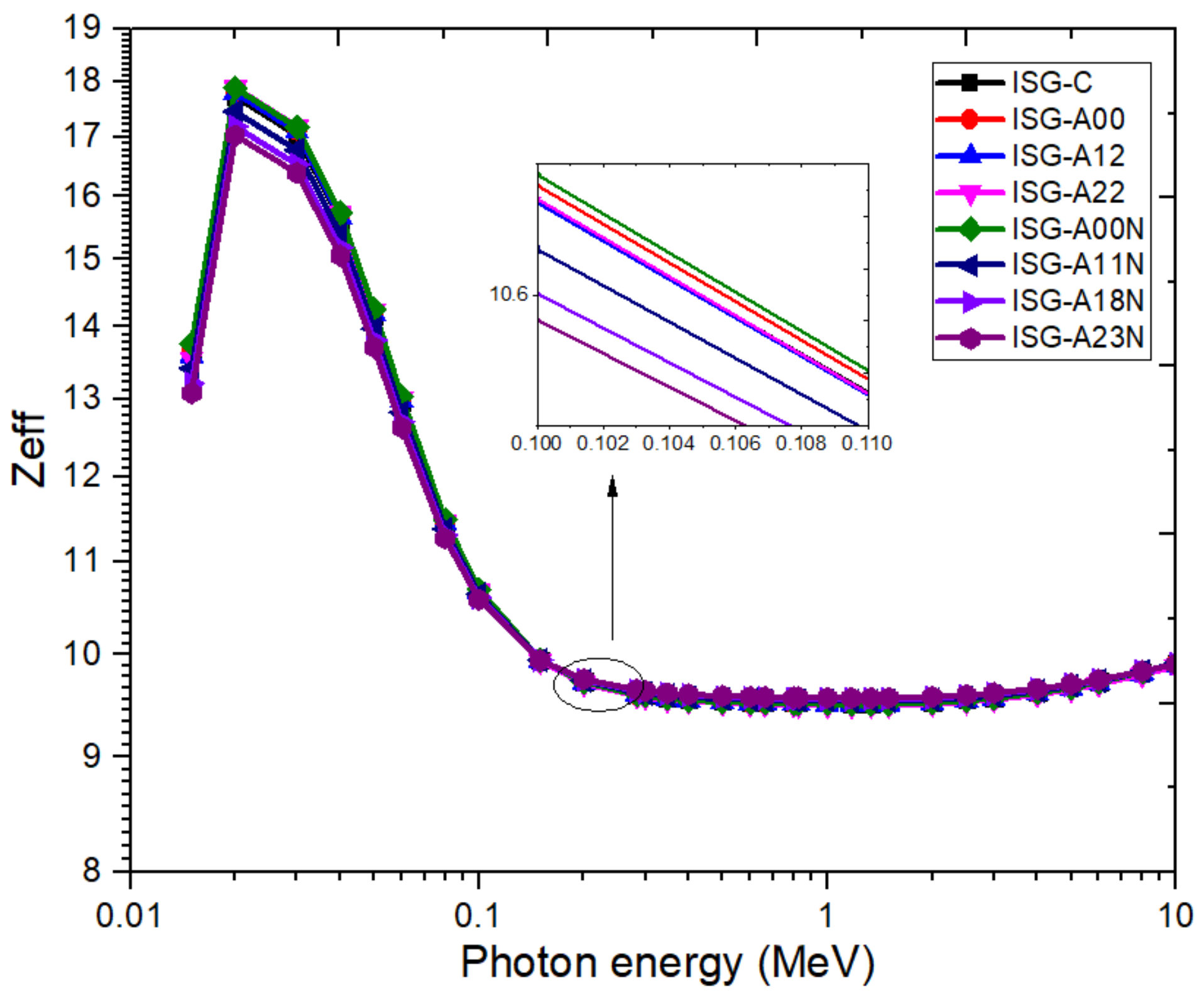

Figure 6

The Zeff for the investigated SiO2-Al2O3-B2O3-Na2O-CaO-ZrO2 glass systems 


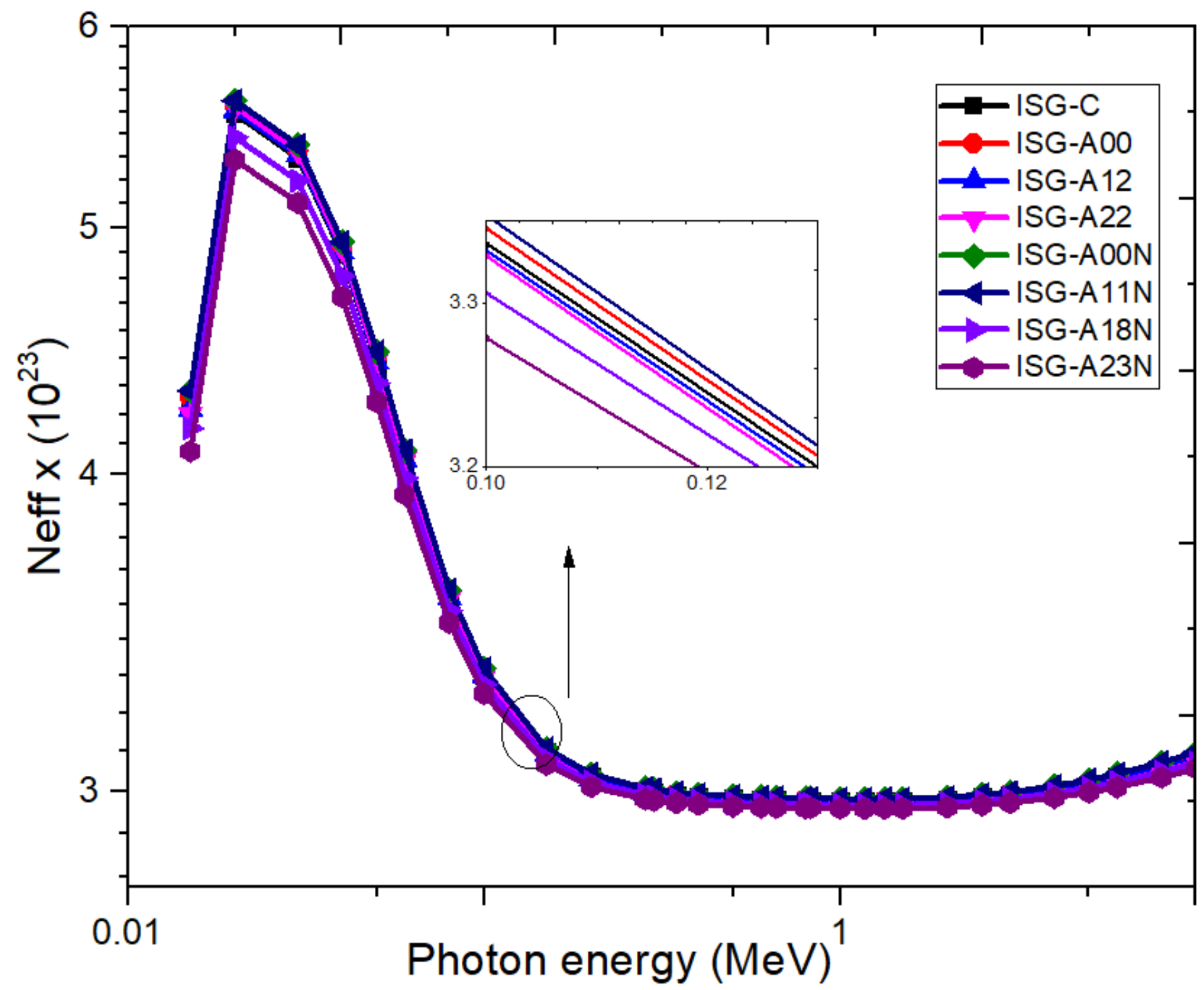

Figure 7

The Neff for the investigated SiO2-Al2O3-B2O3-Na2O-CaO-ZrO2 glass systems 


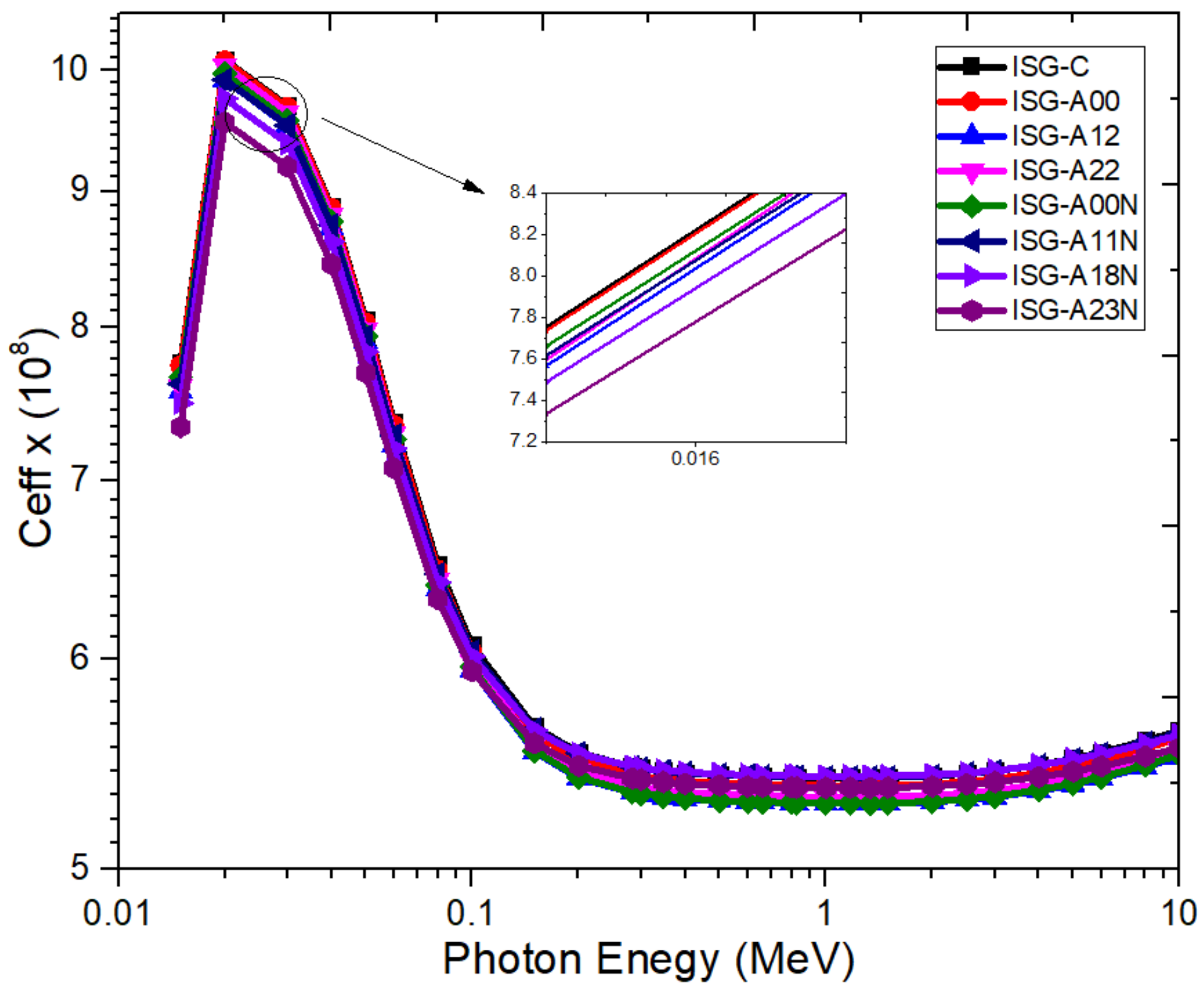

Figure 8

The Ceff for the investigated SiO2-Al2O3-B2O3-Na2O-CaO-ZrO2 glass systems 


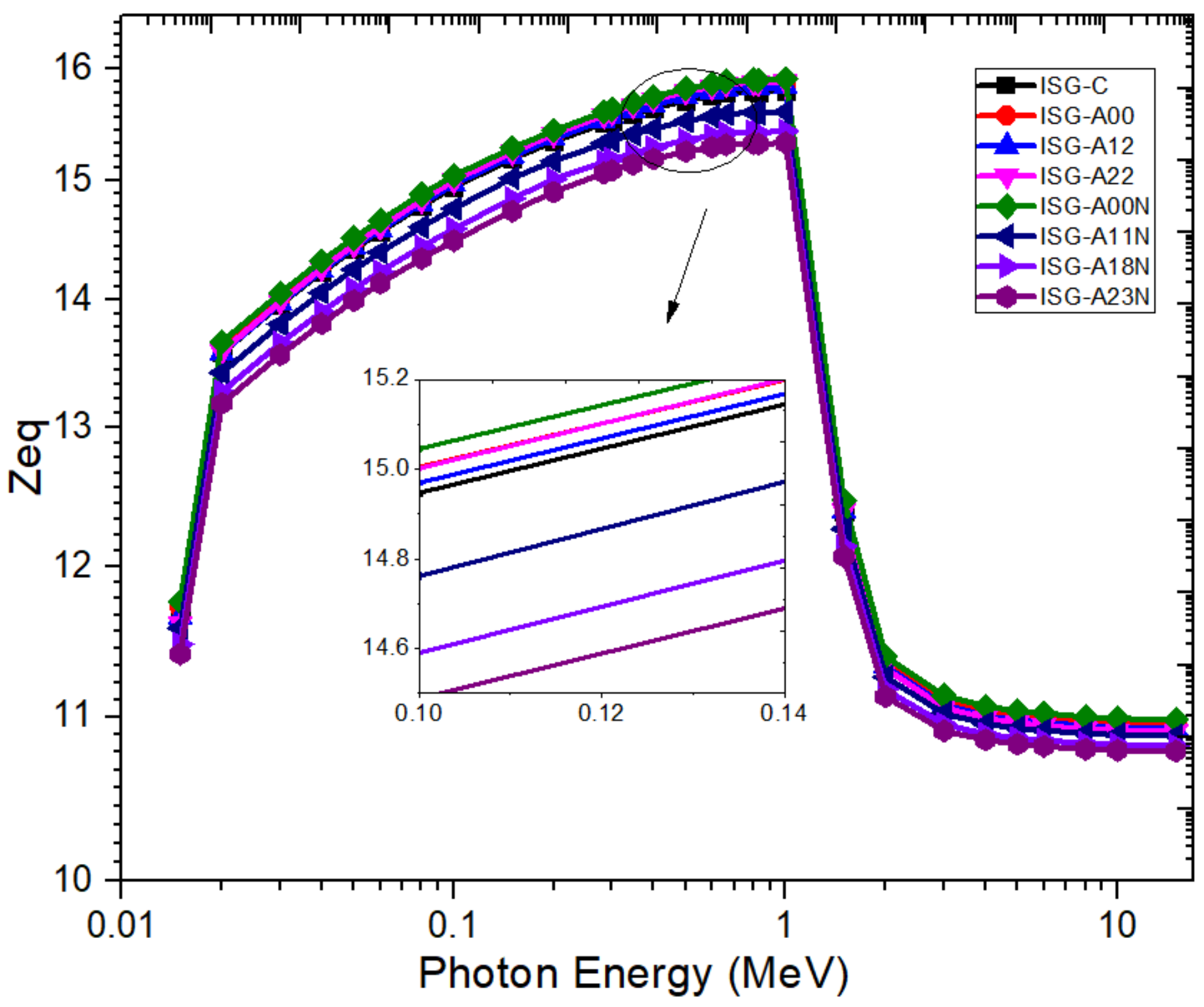

Figure 9

The Zeq for the investigated SiO2-Al2O3-B2O3-Na2O-CaO-ZrO2 glass systems 

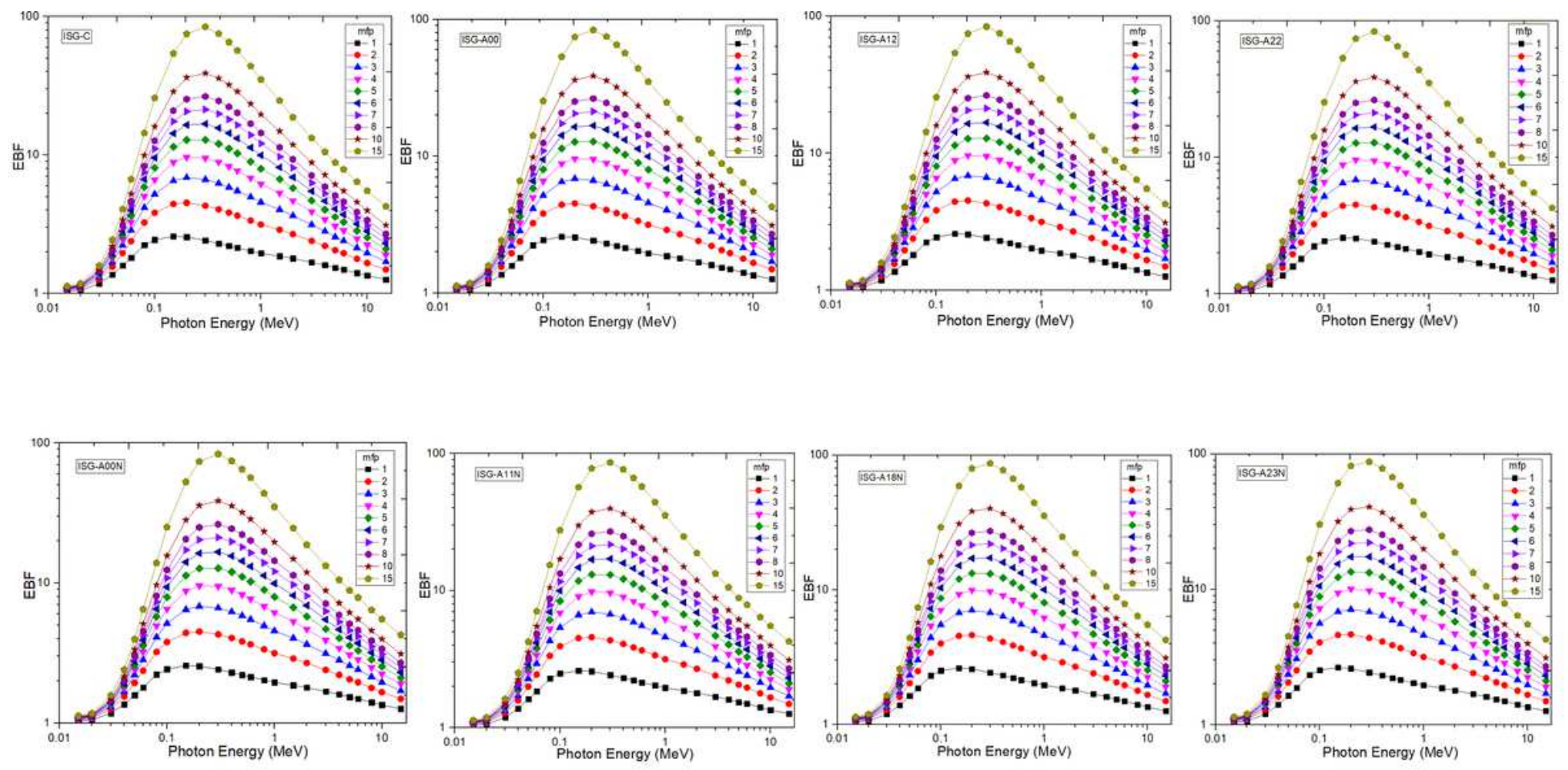

Figure 10

Exposure build-up factor (EBF) against photon energy of samples at 1, 2, 3, 4, 5, 6, 7, 8, 10 and $15 \mathrm{mfp}$ for the investigated SiO2-Al2O3-B2O3-Na2O-CaO-ZrO2 glass systems.
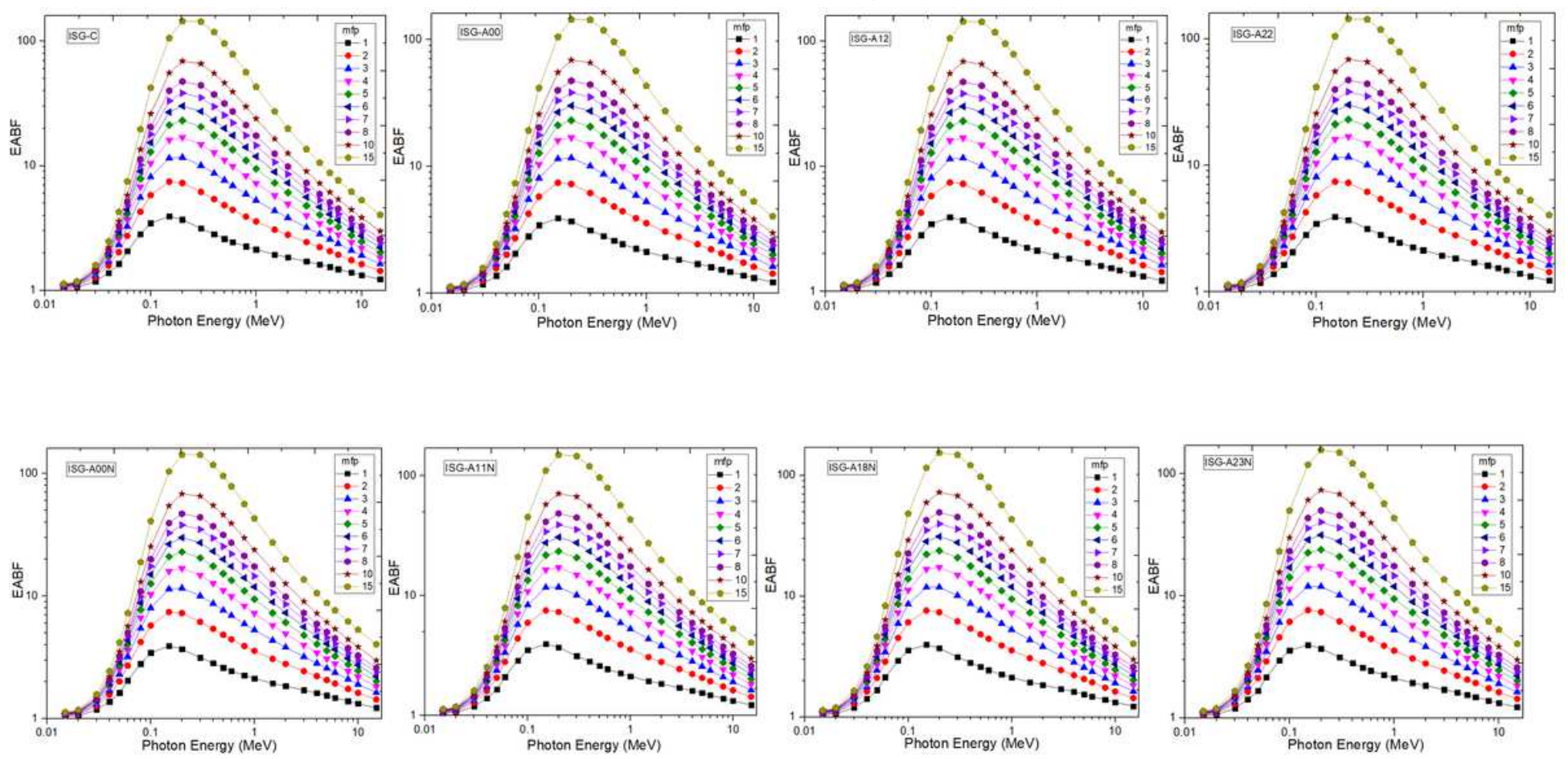

Figure 11 
Energy absorption build-up factor (EBF) against photon energy of samples at 1, 2, 3, 4, 5, 6, 7, 8, 10 and $15 \mathrm{mfp}$ for the investigated SiO2-Al2O3-B2O3-Na2O-CaO-ZrO2 glass systems

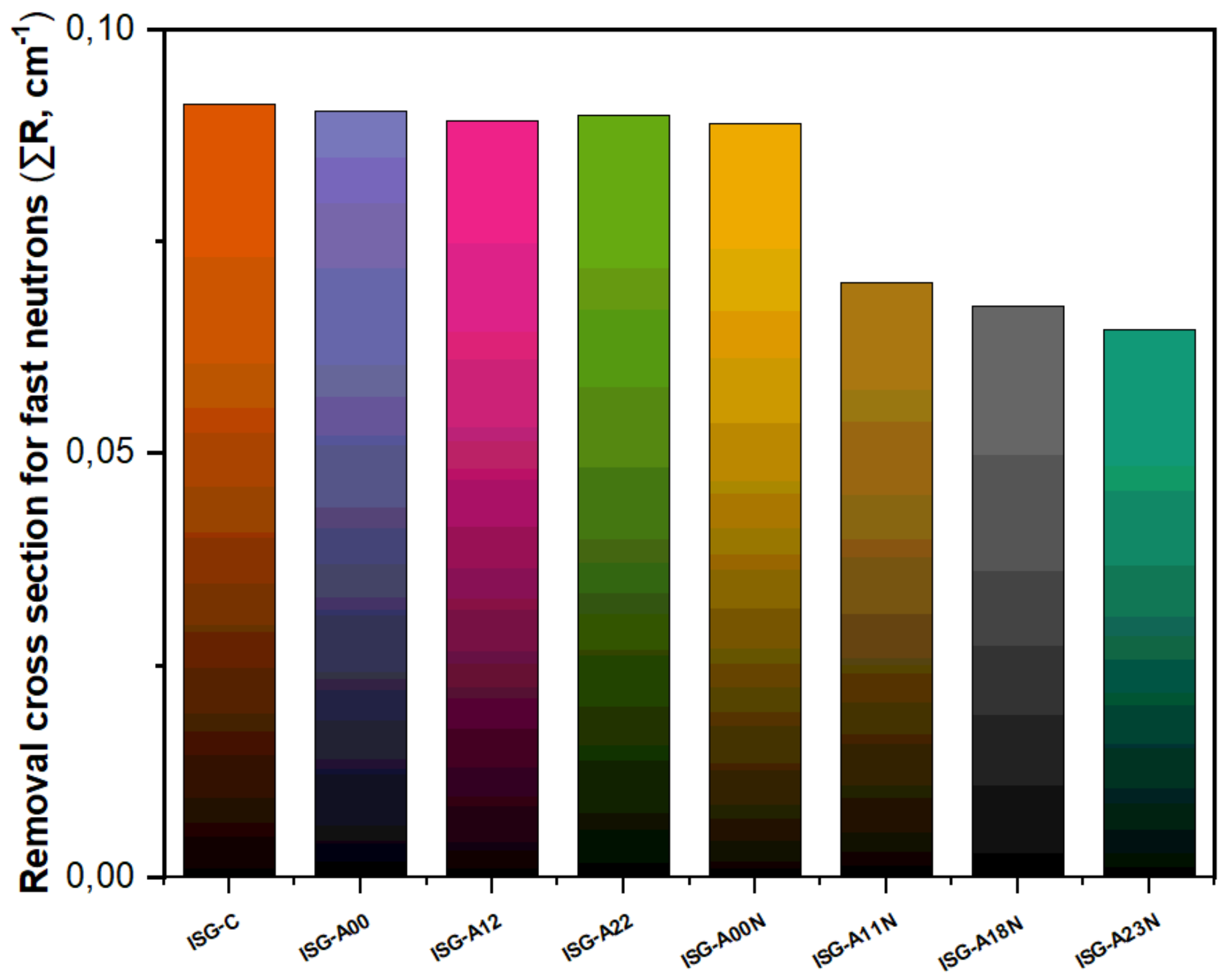

Figure 12

The removal cross section for fast neutrons for the investigated SiO2-Al2O3-B2O3-Na2O-CaO-ZrO2 glass systems 


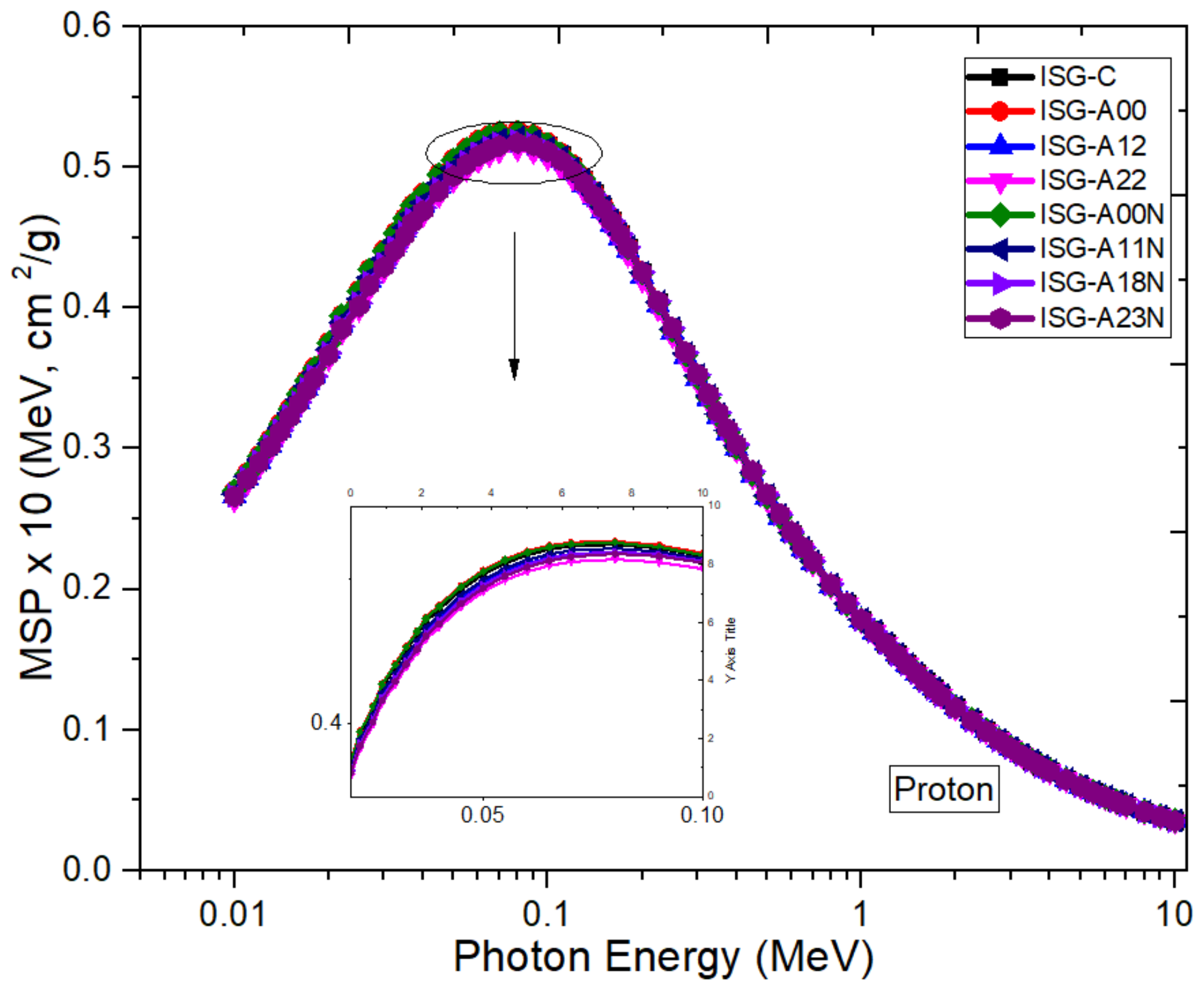

Figure 13

The mass stopping power (proton) for the investigated SiO2-Al2O3-B2O3-Na2O-CaO-ZrO2 glass systems 


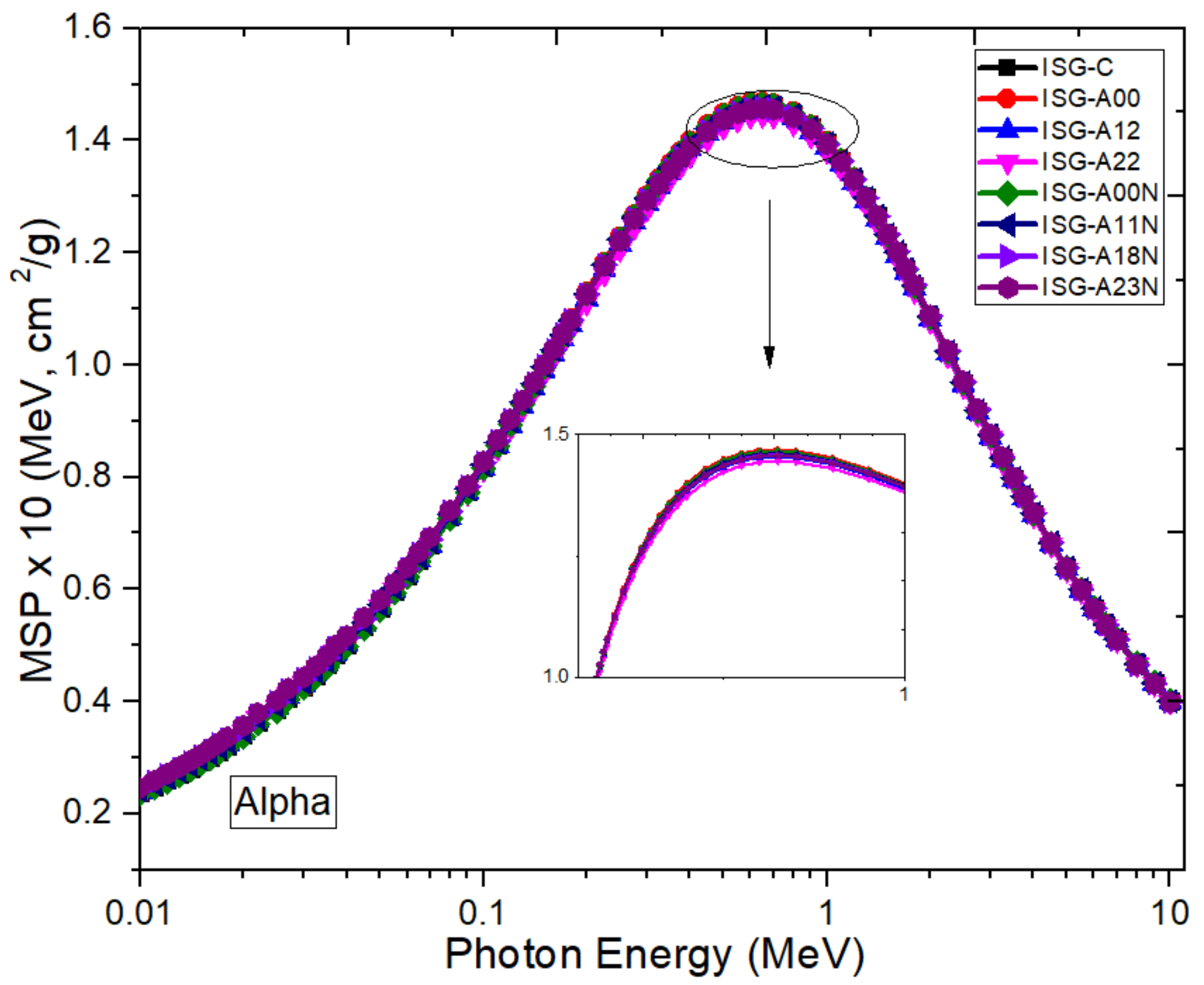

Figure 14

The mass stopping power (proton) for the investigated SiO2-Al2O3-B2O3-Na2O-CaO-ZrO2 glass systems 


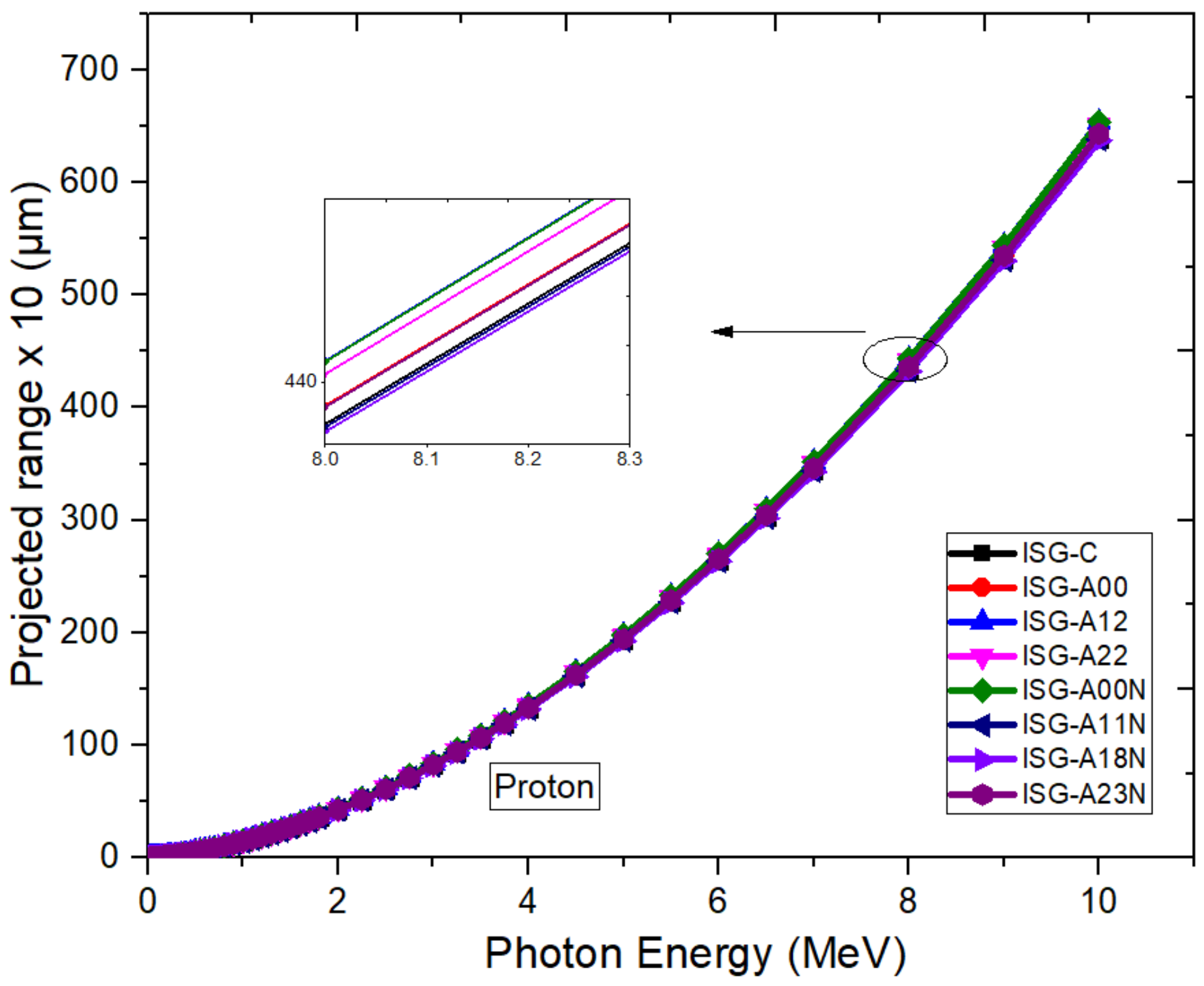

Figure 15

The projected range (alpha) for the investigated SiO2-Al2O3-B2O3-Na2O-CaO-ZrO2 glass systems 


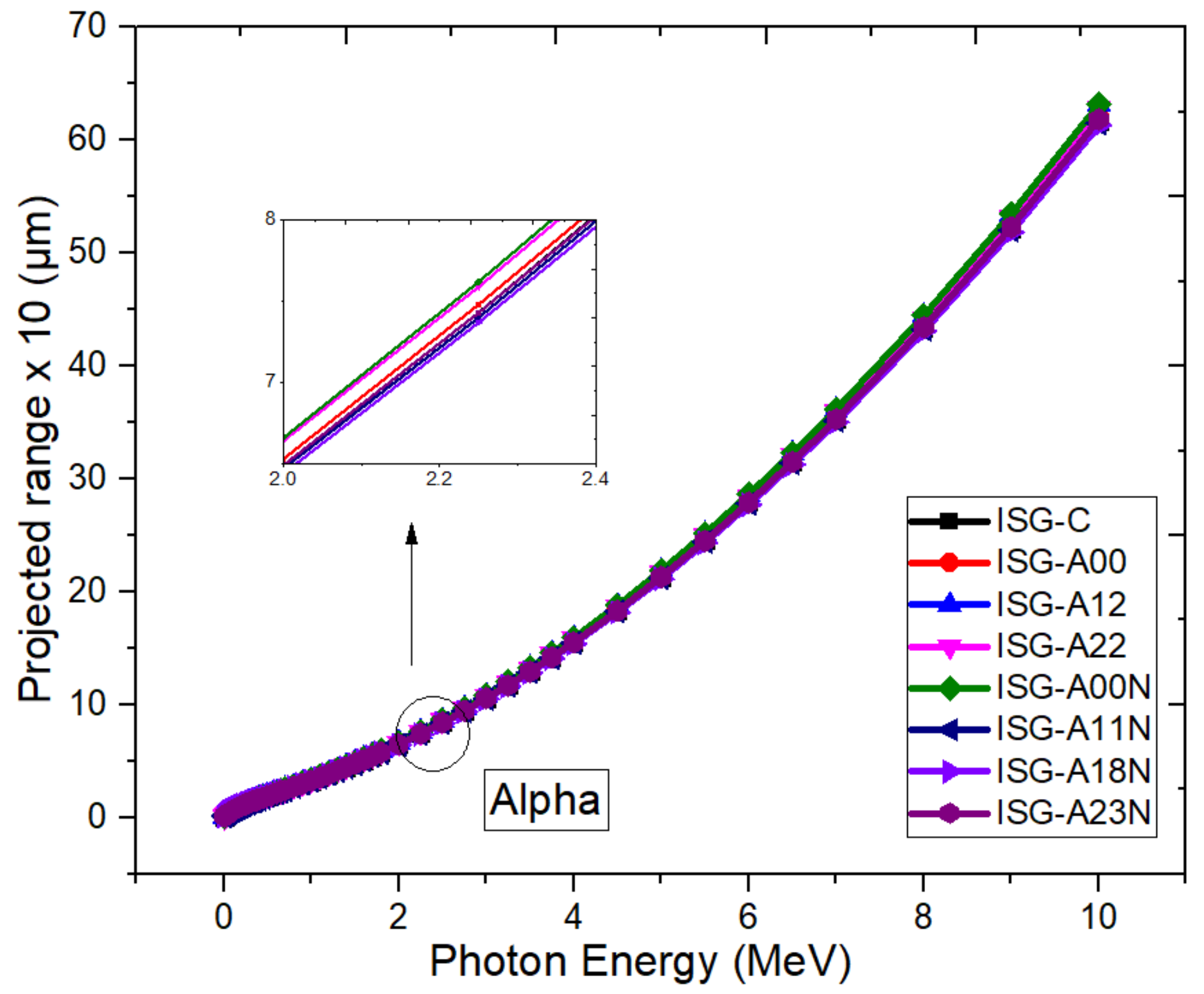

Figure 16

The projected range (proton) for the investigated SiO2-Al2O3-B2O3-Na2O-CaO-ZrO2 glass systems 